\title{
Visco-Plastic Flow of Metal in Dynamic Conditions of Complex Strain Scheme
}

\begin{abstract}
A. KORBEL, W. BOCHNIAK, P. OSTACHOWSKI, and L. BŁAŻ
The article applies to a piece of research inspired by the new technology of plastic metal forming called the KOBO method, which uses the mechanical and structural effects of cyclic changes of deformation path. Its commercial usage in the field of large plastic deformations, especially for the production of extruded elements made of hardly deformable metal alloys, naturally generated a question about the optimal conditions for carrying out the process and the criteria for their establishment, i.e., constitutive description. In this context, the work provides data on the force and energy consumption of aluminum and 7075 aluminum alloy extrusion processes, carried out using the KOBO method, and their dependence on the strain rate and temperature. The mechanism of deformation occurring during extrusion by the KOBO method was identified as visco-plastic flow. Characteristic parameters of the process, such as viscosity coefficiency, activation energy, activated volume, and the concentration of point defects generated during the process were evaluated.
\end{abstract}

DOI: $10.1007 / \mathrm{s} 11661-011-0688-\mathrm{x}$

(C) The Author(s) 2011. This article is published with open access at Springerlink.com

\section{INTRODUCTION}

LOW-TEMPERATURE plastic deformation of metallic materials is accompanied by evolution of the structure resulting in an increase of flow stress and reduction of ductility. Such behavior directly results from the dislocation character of deformation mechanism and densification of dislocation network, which becomes a stronger and stronger obstacle to dislocation slip. However, the structure formed under defined condition of stress and temperature is not stable when these factors spontaneously change or is it altered as a result of external actions. ${ }^{[1-6]}$ Destabilization launches dominance of the localized plastic flow mechanism in the slip bands (single crystals) and shear bands (polycrystalline aggregate), leading to mechanical instability and a reduction in the rate of hardening. If the process takes place in the condition of uniaxial tension at low temperature, and therefore under the influence of high stress and in the presence of high-energy dislocation configuration, shear bands transporting enormous strains may lead to the fracture of the material. A different situation occurs at high temperatures as the localization appears at a very low strain, low stress, and a significantly relaxed structure. In this case, the phenomenon has low dynamics, and as a result of its propagation, the material being deformed may be subjected to a very large plastic deformation without losing coherence.

A. KORBEL, W. BOCHNIAK, and L. BŁAŻ, Professors, and P. OSTACHOWSKI, M.Sc., are with the Faculty of Non-Ferrous Metals, Department of Structure and Mechanics of Solids, AGHUniversity of Science and Technology, 30-059 Cracow, Poland. Contact e-mail: pawel.ostachowski@agh.edu.pl

Manuscript submitted October 5, 2009.

Article published online April 13, 2011
Typically, the increase of plasticity of the material subjected to low-temperature deformation can be achieved by reducing the size of grains; however, their strong fragmentation into nanoscale reverses this relationship. ${ }^{[7-9]}$ Significantly, nanocrystalline materials do not meet the Hall-Petch law, which means that the reduction of grain size does not guarantee the achievement of higher mechanical properties. ${ }^{[10,11]}$ On the other hand, the experimentally observed collapse (reversal) of the Hall-Petch law within the nanocrystalline range suggests the change of the dominant mechanism of deformation, although so far no one has been able to fully identify the structural phenomena responsible for this effect.

One of the most attractive properties of fine-grained metallic materials revealed especially during deformation at elevated temperatures $\left(\sim 0.5 T_{\text {melt }}\right)$ at strain rates between $10^{-4}$ and $10^{-2} \mathrm{~s}^{-1}$ is superplasticity, i.e., the ability to carry extremely high plastic strain. Superplasticity is characterized by strain rate sensitivity $m>$ $0.3(m=\delta \ln \sigma / \delta \ln \varepsilon)$, low flow stress, and zero or a very low rate of hardening. If the strain rate sensitivity equals 1 , the typical dependence between flow stress, $\sigma$, and strain rate, $\hat{\varepsilon}$, usually described using the formula $\sigma=k \cdot \dot{\varepsilon}^{m}$ (where $k=$ constant), would receive a form of Newton's laminar flow principle $\sigma=\eta \cdot \hat{\varepsilon}$ (where $\eta=$ viscosity coefficiency). In this case, the material subjected to deformation, although solid, will behave like a liquid.

Based on structural observations, it was found that just after the initiation of the superplastic flow process, shear bands appear in the material. ${ }^{[12]}$ Moreover, in contrast to deformed materials with micrometric grain sizes, deformed nanomaterials do not show the presence of dislocation, in particular, the characteristic dislocation tangles. ${ }^{[13,14]}$ The strain rate sensitivity for 
nanocrystalline materials tested at low temperatures (ambient temperature) is small and usually does not exceed the value of $0.02 .^{[9]}$ However, the fact that superplasticity occurs in higher temperatures and at a limited regime of strain rate tends to draw attention to the thermally activated dislocation movement and migration of point defects. In the latter case, one must specify the Nabarro-Herring creep, which is directed by stress, diffusive process inside the grains, and Coble creep covering grain boundaries. It is believed ${ }^{[15]}$ that up to 50 pct of atoms forming nanometals may be within grain boundaries; in particular, the case of material with grains of $10 \mathrm{~nm}$, from 14 to 27 pct of all the atoms, of which it is built, is located in the areas of grain boundaries with a width of 0.5 to $1.0 \mathrm{~nm} .^{[10]}$ Therefore, the significant role of grain boundaries in the process of deformation is emphasized, ${ }^{[16-18]}$ at the cost of transcrystalline mechanisms based on dislocation activity and Nabarro-Herring creep; however, on the other hand, the deformation mechanism based solely on Coble within grain boundaries is not real. ${ }^{[19]}$

Similarly, as was initially stated for the alloys with grain size of a few micrometers, ${ }^{[20]}$ also in the case of nanomaterials, it is possible that a slip along grain boundaries may take place. This is confirmed by the results of structural investigations of deformed nanomaterials using a scanning microscope. Direct observations certify the continuous presence of these same grains. ${ }^{[21]}$

Slip along grain boundaries, Coble creep, and the mechanism involving grain rotation ${ }^{[22-24]}$ recently became the subject of particular interest during the simulation and analytical studies. ${ }^{[25-29]}$ A concept that combines the phenomenon of superplasticity and slip along the grain boundaries, despite many controversial assumptions, has been found to be justified. ${ }^{[2,30,31]}$ On the other hand, the smaller the grains, the larger the area occupied by the boundaries; their spatial distribution is also better, allowing a long-range intercrystalline shear. It is highly likely that due to the nature of the shear, it will also be present inside some grains. This phenomenon would be accompanied by, first of all, an accommodative Coble creep ensuring the compliance of strain in the adjacent areas.

Despite many diverse concepts of superplastic flow phenomenon, it seems reasonable to say that, regardless of the type of material, it is caused by the same physical mechanism. ${ }^{[32]}$

If the phenomenon of superplastic flow in the dominant extent is the displacement (moving or revolutions) of one nanograin in relation to the others, the question is raised regarding the similarity in behavior of the nanoblocks "cut" from any large grains by intersecting (micro) shear bands. In other words, whether it is possible that, due to the localized plastic flow of the material with large grains, it gains superplastic properties? In this article, the answers to this question were searched for, both on the basis of analysis and, first of all, experiments, using the KOBO method that guarantees the implementation of severe plastic deformation (SPD) during the extrusion of aluminum and its 7075 alloy.

\section{KOBO METHOD}

There are a number of SPD methods that lead to the creation of a fine (nano) crystalline structure in materials as a result of the phenomenon of intensive localized plastic flow in the form of shear bands. Among these, the most famous include equal-channel angular pressing (ECAP), ${ }^{[33-38]}$ high-pressure torsion (HPT), ${ }^{[39-42]}$ and accumulative roll bonding (ARB). ${ }^{[43-46]}$ Unfortunately, the industrial use of nanocrystalline materials obtained by the preceding methods is not always justified because of the low efficiency of the process, significantly limited dimensions (mass) of products, and the inhomogeneity of their structure. ${ }^{47-49]}$

Recently, another SPD method called the KOBO method was developed. This method can be used during plastic forming of materials in typical processes, such as extrusion, pressing (forging), rolling, or drawing. ${ }^{[50]}$ KOBO guarantees highly fragmented and homogeneous structure of products. ${ }^{[51,52]}$ It consists of inducing cyclic changes of the deformation path in material being subjected to deformation as a result of the cyclic change of the straining scheme. Consequently, there is a permanent destabilization of the structure and the dominance of localized plastic flow in the intersecting shear bands. Such a procedure allows the extrusion process to be conducted at low temperature ("cold working"), i.e., without preheating the material and at a higher strain rate and also higher extrusion ratio than when carried out on conventional extrusion ("hot working"). Moreover, the product has a fine (nano) grain structure and very favorable mechanical properties.

Regardless of the proven and potential advantages of the KOBO method, a whole range of problems, both practical (optimization of technological parameters) and cognitive issues, remain unsolved. This is due to the fact that the proposed solution is the first of its type and there is a lack of complete data documenting the mechanical characteristic of the process. Having them would make it possible to conduct an analysis from both the mechanics of plastic flow and the structural events points of view. The number of variables of the extrusion process, such as extrusion ratio $\lambda$ (strain magnitude), temperature, and rate of extrusion, is increased in the KOBO method by torsion parameters of deformed material, i.e., angle and the frequency of reversible rotation of the die.

To examine the relationships between all these parameters and their combined impact on the course of extrusion, it is necessary to carry out a complete analysis of the process, especially since there are attempts of its modeling. ${ }^{[5]}$ In the absence of knowledge about other physical reasons, it is assumed here that the reduction in extrusion force is directly associated with the additional increase in temperature of the deformed material due to work of torque (reduction of plastic flow resistance).

However, the question remains open regarding the documented reasons of extrusion force reduction, and, above all, the energy-consumption of the process and mechanisms of plastic flow induced in such complex conditions of deformation. 


\section{RESEARCH METHODOLOGY}

Experiments included the extrusion process with the KOBO method (Figure 1) and conventional extrusion of technically pure aluminum and hardly deformable 7075 alloy using a press with nominal load of $1000 \mathrm{kN}$. The materials chemical composition is presented in Table I.

Billets $65-\mathrm{mm}$ long with a diameter of $40 \mathrm{~mm}$ were extruded to wires with diameters of $4,6,8$, and $12 \mathrm{~mm}$ (extrusion ratio $\lambda$ : 100,44.4, 25, and 11), which correspond to true strains of $4.6,3.8,3.2$, and 2.4, respectively. The process was conducted at temperatures $293 \mathrm{~K}, 373 \mathrm{~K}, 473 \mathrm{~K}$, and $573 \mathrm{~K}\left(20^{\circ} \mathrm{C}, 100{ }^{\circ} \mathrm{C}, 200{ }^{\circ} \mathrm{C}\right.$, and $300{ }^{\circ} \mathrm{C}$ ), and in the case of 7075 alloy at $673 \mathrm{~K}$ $\left(400{ }^{\circ} \mathrm{C}\right)$ as well, at a constant ram speed (extrusion rate $v_{w}$ ) in the range of 0.09 to $0.5 \mathrm{~mm} / \mathrm{s}$. The cyclically rotating part of the die had an outer diameter of $35 \mathrm{~mm}$ and oscillated at an angle of \pm 8 deg with a constant frequency within the range of 2 to $8 \mathrm{~Hz}$.

During the process, the extrusion force, torsion force acting on the die arm of the crank system (Figure 1(a)), and the displacement of the punch as a function of time were recorded.

Structural studies were also carried out on samples taken from the extrusion butts, in particular, from the shear zone.

\section{MECHANICAL CHARACTERISTICS OF EXTRUSION WITH THE KOBO METHOD}

Generally speaking, the mechanical characteristics recorded during conventional extrusion in the of extrusion force vs punch displacement (distance) reveal two typical behaviors. Under the conditions of direct extrusion, after initiation of the process, there is a decrease of the extrusion force observed, while in the case of indirect extrusion, the force remains at a constant level. The reason for the reduction of the extrusion force is the friction of extruded material against the container, as a result of the billet upset under the action of extrusion force. Decreasing the friction surface with a reduction of the length of the billet leads to lower friction force and, thus, reduces the extrusion force.

As presented in Figures 2 through 4, for example, for the 7075 alloy, extrusion with the cyclically oscillating die (the KOBO method) reveals both types of behavior. The second important piece of information from the tests carried out is a confirmation of the possibility of cold (without preheating) plastic forming of hardly deformable 7075 alloy, with a very high extrusion ratio $\lambda$ equal to 100 and under a relatively low extrusion force. In the particular case of aluminum, it was possible to obtain $\lambda=256$ at the extrusion rate of $0.18 \mathrm{~mm} / \mathrm{s}$ (Figure 5) not involving the maximum load of the press. An extrusion ratio of $\lambda=711$ is also obtainable, although at that time, it reached a maximal achievable force of the extrusion of $1070 \mathrm{kN}$ (Figures 6 and 7), at which there is the presence of a "temporarily stationary" state of force at an initial extrusion rate of $0.15 \mathrm{~mm} / \mathrm{s}$ (Figure 7).

What is most important, however, is the experimentally determined relationships between maximal extrusion force and extrusion strain rate (punch velocity), which are linear (Figures 8 and 9) and, thus, reveal yet another aspect of the extrusion process with the KOBO method. Moreover, Figure 10 shows that the linear dependence of the extrusion force from the extrusion rate is an independent feature from the preheated temperature of metal. Just this information became an important premise for the analysis of the plastic flow mechanism presented later in this work.

Both the magnitude of strain resistance (sum of the resistance of plastic flow and frictional resistance at the metal-tool contact) at which it is possible to extrude cold metal (extrusion of aluminum and its alloys is usually carried out at temperatures above $673 \mathrm{~K}$ $\left(400{ }^{\circ} \mathrm{C}\right)$, and a much lower extrusion ratio $\lambda$ ) and the nature of dependency from the extrusion rate raise the question of the energy cost of the process assisted by torsional moment work. The answer to this question may be provided by the analysis of combined effect (energy balance) of extrusion force work and torque work. Limiting the analysis mainly to the initiation of the process at which these two quantities have a maximum value, defined as a momentary work of punch or power consumption $L_{w}\left(L_{w}=F_{w} \cdot v_{w} \mathrm{~J} / \mathrm{s}\right.$, where $F_{w}=$ extrusion force and $v_{w}=$ true rate of extrusion) and momentary torsion work $L_{m}\left(L_{m}=F_{m}\right.$. $R \cdot 2 \varphi \cdot f \mathrm{~J} / \mathrm{s}$, where $F_{m}=$ torsion force, $R=$ arm length of the applied force, $\varphi=$ torsion angle, and $f=$ torsion frequency), the change in temperature of metal as a result of the conversion of deformation work into heat, in relation to the state prior to extrusion, is the smallest, so the quantities can be related to the initial temperature.

Figure 11 shows the behavior of the 7075 alloy, dependence of total (maximum) power consumption at the peak of force of the extrusion $\left(L_{w}+L_{m}\right)$ and the ratio of momentary torsion work and momentary work of punch $L_{m} / L_{w}$ on the strain (extrusion ratio $\lambda$ ) at true rate of extrusion $v_{w}=0.18 \mathrm{~mm} / \mathrm{s}$ and at room temperature (without heating the charge). Figure 12 presents the quantities $\left(L_{w}+L_{m}\right)$ and $L_{m} / L_{w}$ as a function of extrusion rate at constant value of $\lambda=100$.

Decreasing $L_{m} / L_{w}$ quotient along with extrusion ratio (Figure 11) means that at a fixed torsion frequency (in this case $5 \mathrm{~s}^{-1}$ ) and constant extrusion rate $v_{w}=0.18 \mathrm{~mm} / \mathrm{s}$, due to lower fraction of moment work, it is more beneficial to run the process with high extrusion ratio $\lambda$. Simultaneously, strong dependence of this parameter on extrusion rate (Figure 12) suggests that the reasons for such a behavior might be found in the increase of extrusion rate, which increases along with increase of extrusion ratio. This tendency is well presented in Figures 13 and 14. Assuming that at a fixed geometry of tools (container, die) the contribution of frictional resistance does not depend on the extrusion rate, the power consumption of the process at a certain rate can be referred to as the volume of metal extruded in unit time through the die. The obtained parameter $\left(L_{w}+L_{m}\right) /\left(v_{w} \cdot A_{o}\right)$ may be used as the measure of maximal energy consumption of the process in conditions defined by the extrusion ratio as well as temperature and extrusion rate. 


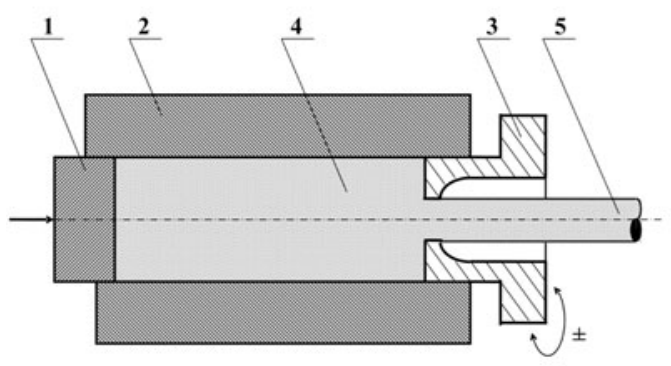

(a)

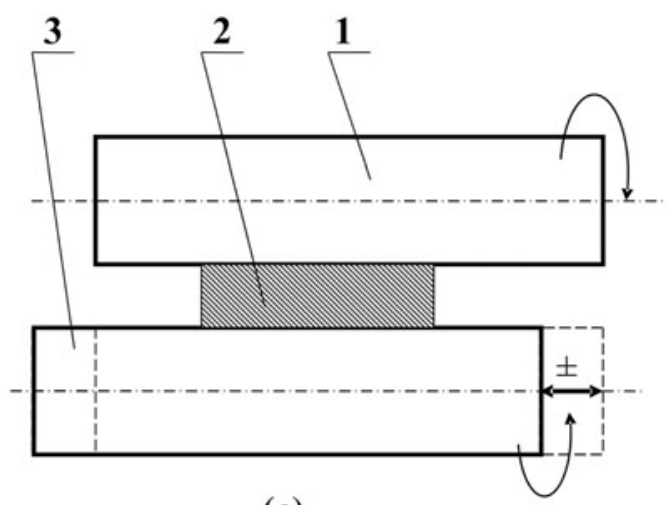

(c)

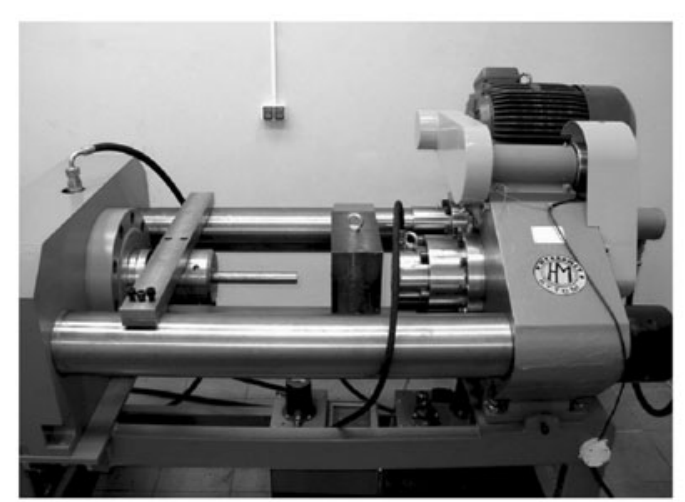

(e)

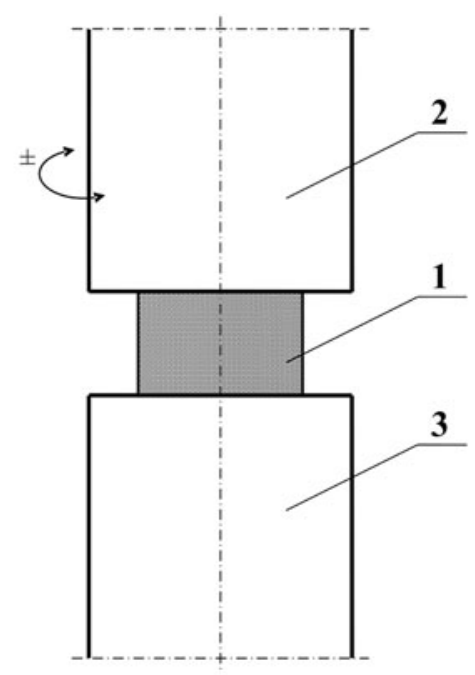

(b)

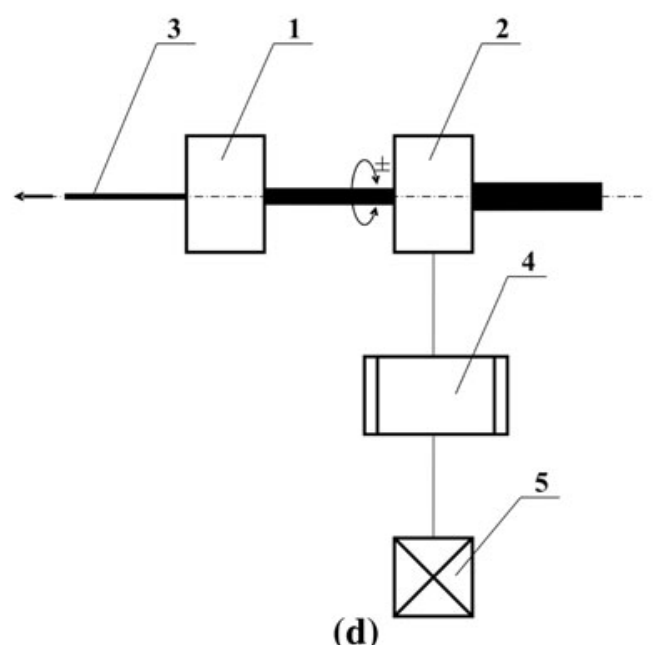

(d)

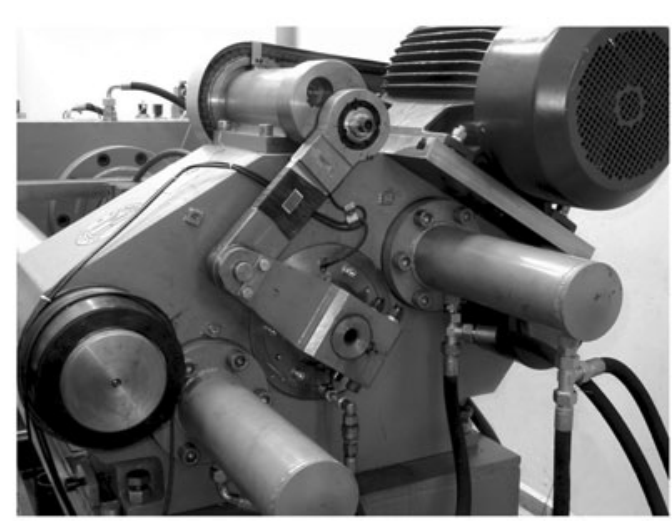

(f)

Fig. 1-Deformation of metallic materials with the KOBO method in the process of (a) 1-punch, 2-reversaly rotated die, 3 - container, 4 -extruded material, 5-product; forging $(b) 1$-metal, 2-reversaly rotated punch, 3-die/anvil; rolling $(c) 1$-metal, 2-upper roll, 3 - cyclically, axially shifted bottom roll; and drawing (d) 1-immobilized drawing die, 2- reversely rotated drawing die, 3-metal, 4-gear box, 5-engine. (e) General view of $1000 \mathrm{kN} \mathrm{KOBO}$ press $(f)$ with the crank system of the reversible rotation of the die.

The diagrams presented in Figures 14 and 15 indicate that a decrease (along with extrusion rate) of extrusion work per a unit volume of metal is a process attribute that is independent of both the material's type and its extrusion ratio as well as its extrusion temperature. It should be recalled here, once again, that numerical 
Table I. Chemical Compositions (Weight Percent) of Materials Used for Testing

\begin{tabular}{lcccccccccccccc}
\hline Material & $\mathrm{Cu}$ & $\mathrm{Fe}$ & $\mathrm{Mn}$ & $\mathrm{Zn}$ & $\mathrm{Mg}$ & $\mathrm{Si}$ & $\mathrm{Ni}$ & $\mathrm{Ti}$ & $\mathrm{Cr}$ & $\mathrm{V}$ & $\mathrm{Ga}$ & $\mathrm{Pb}$ & $\mathrm{Zr}$ \\
\hline 7075 & 1.714 & 0.367 & 0.251 & 5.453 & 2.339 & 0.181 & 0.002 & 0.020 & 0.185 & - & - & - & 0.06 \\
$\mathrm{Al}$ & 0.005 & 0.197 & 0.004 & 0.018 & 0.008 & 0.068 & 0.002 & 0.018 & 0.003 & 0.0019 & 0.009 & 0.004 & - \\
\hline Cont. & $\mathrm{Na}$ & $\mathrm{B}$ & $\mathrm{P}$ & $\mathrm{Be}$ & $\mathrm{Ca}$ & & & & & \\
\hline $\mathrm{Al}$ & 0.0004 & 0.0019 & 0.0010 & 0.0000 & 0.0009 & & & & & \\
\hline
\end{tabular}

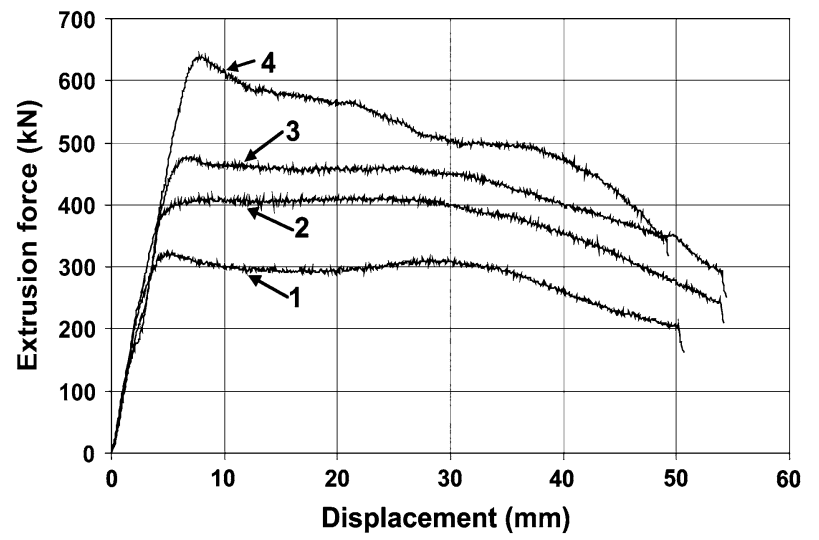

Fig. 2-Extrusion load-punch displacement characteristics of the KOBO process obtained for different extrusion ratios $\lambda$ at room temperature and extrusion rate $0.18 \mathrm{~mm} / \mathrm{s}$ (oscillation frequency $f=5 \mathrm{~Hz}$, angle $\alpha= \pm 8 \mathrm{deg}$ ). Note: curve 1 corresponds to $\lambda=11$, curve 2 to $\lambda=25$, curve 3 to $\lambda=44.4$, and curve 4 to $\lambda=100$.

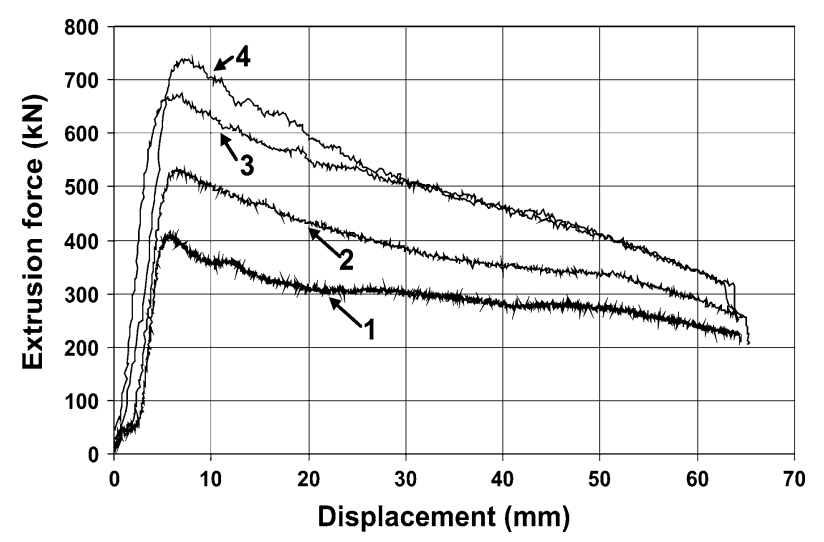

Fig. 3-Influence of extrusion rate on load characteristics of the KOBO extrusion at room temperature $(\lambda=100, f=5 \mathrm{~Hz}$, $\alpha= \pm 8 \mathrm{deg}$ ). Note: curve 1 corresponds to $V_{p}=0.5 \mathrm{~mm} / \mathrm{s}$, curve 2 to $V_{p}=0.33 \mathrm{~mm} / \mathrm{s}$, curve 3 to $V_{p}=0.18 \mathrm{~mm} / \mathrm{s}$, and curve 4 to $V_{p}=0.09 \mathrm{~mm} / \mathrm{s}$.

values of the parameter $\left(L_{w}+L_{m}\right) /\left(v_{w} \cdot A_{o}\right)$ were obtained using a press with particular tools geometry and with fixed angle and frequency of die oscillation.

The influence of the die oscillation frequency on extrusion force and torque as well as on diagram form is shown in Figure 16. It reveals a strong interdependence between extrusion force, torsion force, extrusion rate, and torsion frequency. Figure 17 illustrates the influence

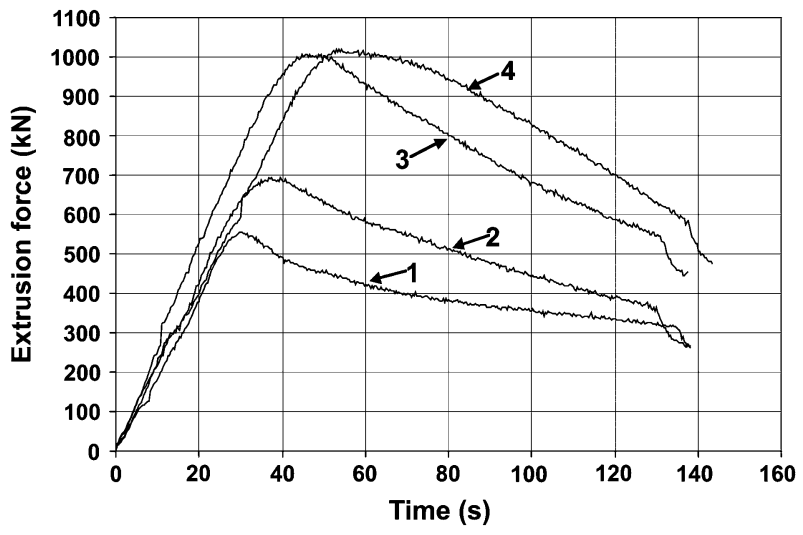

Fig. 4-Influence of extrusion temperature on load characteristics of the KOBO process at the extrusion rate of $v_{w}=0.18 \mathrm{~mm} / \mathrm{s}$ and extrusion ratio of $\lambda=100(f=5 \mathrm{~Hz}, \alpha= \pm 8 \mathrm{deg})$. Note: curve 1 corresponds to $T=673 \mathrm{~K}\left(400{ }^{\circ} \mathrm{C}\right)$, curve 2 to $T=693 \mathrm{~K}$ $\left(220^{\circ} \mathrm{C}\right)$, curve 3 to $T=373 \mathrm{~K}\left(100{ }^{\circ} \mathrm{C}\right)$, and curve 4 to $T=273 \mathrm{~K}$ $\left(20{ }^{\circ} \mathrm{C}\right)$.

of frequency on torsion force. However, the synergy of the mentioned parameters shows that only at frequencies of 5 and $8 \mathrm{~Hz}$ is the assigned extrusion rate $(0.5 \mathrm{~mm} / \mathrm{s})$ maintained. At lower frequencies, the true extrusion rate was smaller than assigned, which makes it more difficult to determine the relationship in numbers. However, lowering the torsion force by 50 pct along with the increase of frequency from 5 to $8 \mathrm{~Hz}$ (at the extrusion rate of $v_{w}=0.5 \mathrm{~mm} / \mathrm{s}$ ) proves that power input to the torsional system is lowered by 25 pct. Simultaneously, increasing the frequency results in the extrusion force decreasing as well, and the course of the force-distance relationship changes. Initially, the relationship reminds one of direct extrusion with a typical decrease of extrusion force (Figures 16(a)); later it is similar to the stationary process, which is characterized by constant extrusion force, torque, and, importantly, constant extrusion rate (Figures 16(c) and (d)). In conditions set up by the power output of the power transmission system of the press, stationary states for extrusion ratio of $\lambda=100$ and initial length of billet equal to $65 \mathrm{~mm}$ were obtained at true extrusion rates lower than $0.5 \mathrm{~mm} / \mathrm{s}$ (Figures 16(b) and (d)) or at the rate of $0.5 \mathrm{~mm} / \mathrm{s}$ (the highest speed of punch, limited by pump capacity in hydraulic system) when the frequency equaled $8 \mathrm{~Hz}$.

On the basis of the results obtained, one may suppose that the reduction of extrusion force, as in the case presented in Figure 16(a), means "the acceleration of 


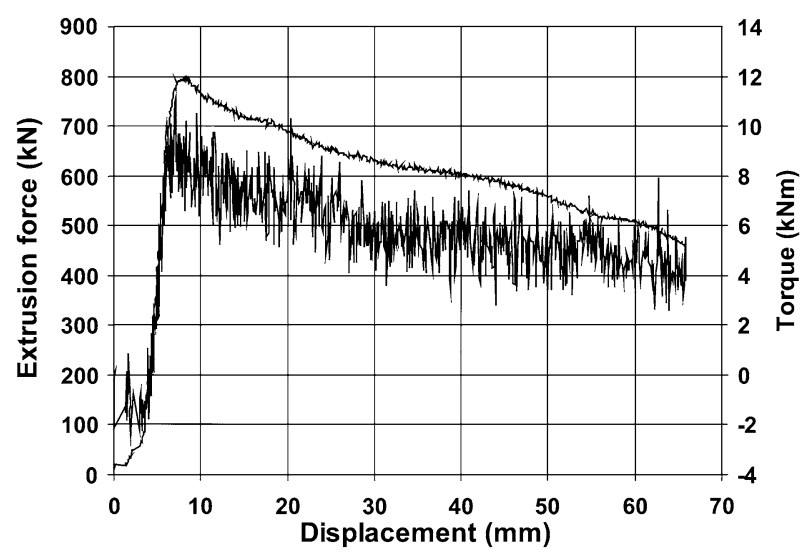

Fig. 5-Dependence of extrusion force (upper line) and torque (bottom line) on punch displacement, for aluminum subjected to the KOBO process $\left(\lambda=256, v_{w}=0.18 \mathrm{~mm} / \mathrm{s}\right)$.

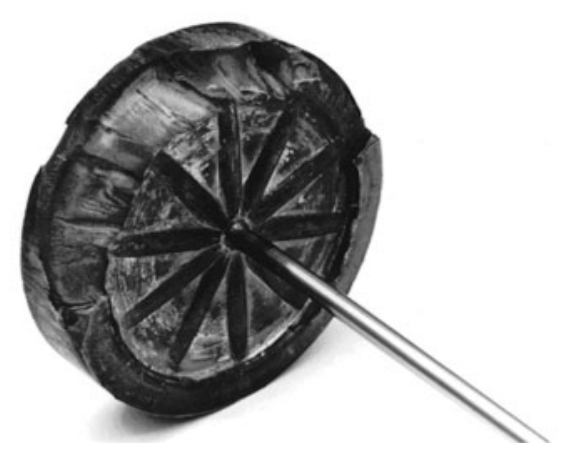

Fig. 6-Butt and fragment of extruded aluminum wire. Wire diameter $1.5 \mathrm{~mm}\left(\lambda=711, T=293 \mathrm{~K}\left(20^{\circ} \mathrm{C}\right)\right)$.

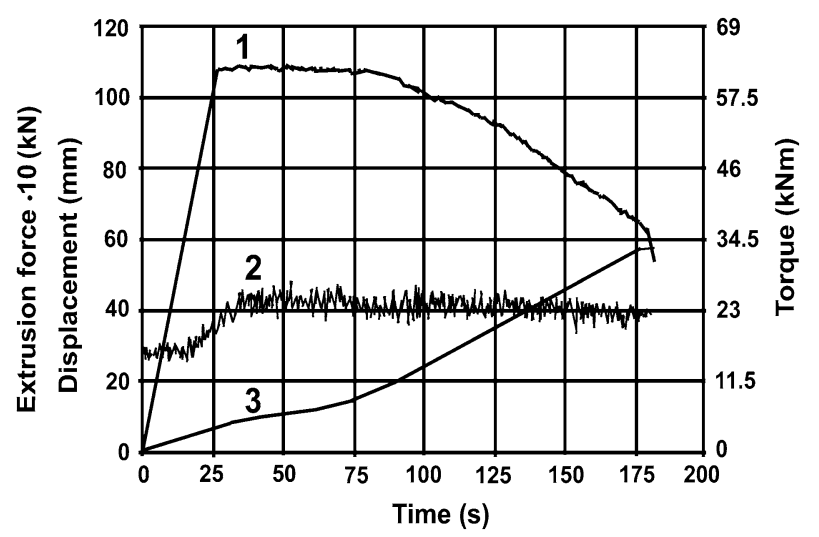

Fig. 7-Dependence of extrusion force (1), torque (2), and punch displacement (3) on time, for aluminum extruded with extrusion ratio of $\lambda=711$ at room temperature (initial, true extrusion rate $v_{w}$ was $0.33 \mathrm{~mm} / \mathrm{s}$ ). State of temporarily stationary extrusion force (plateau-upper curve) and torque (middle curve).

the process" to a certain stationary state at which the true extrusion rate would be greater than assigned. This limits the extrusion force, as well as oscillation frequency, which causes a reduction in the true extrusion

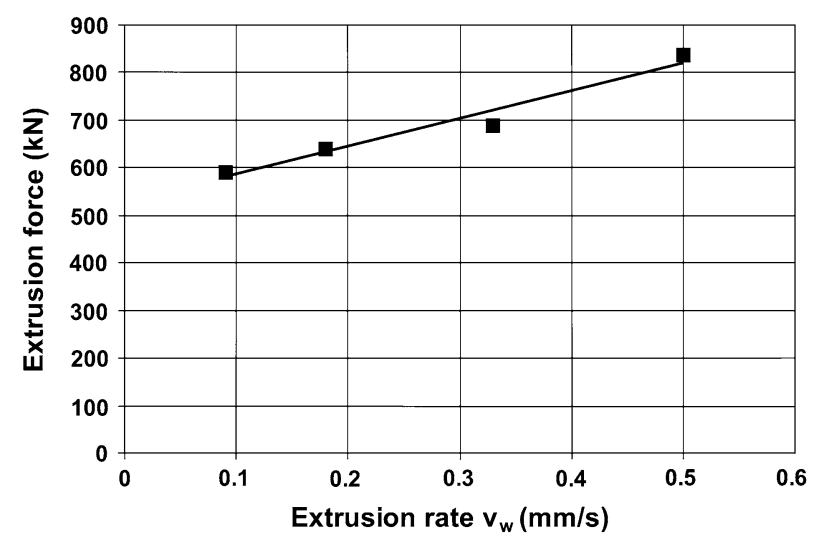

Fig. 8-Dependence of maximal extrusion force on extrusion rate $v_{w}$ of 7075 alloy $\left(\lambda=100, f=5 \mathrm{~Hz}, T_{o}=293 \mathrm{~K}\left(20^{\circ} \mathrm{C}\right)\right)$.

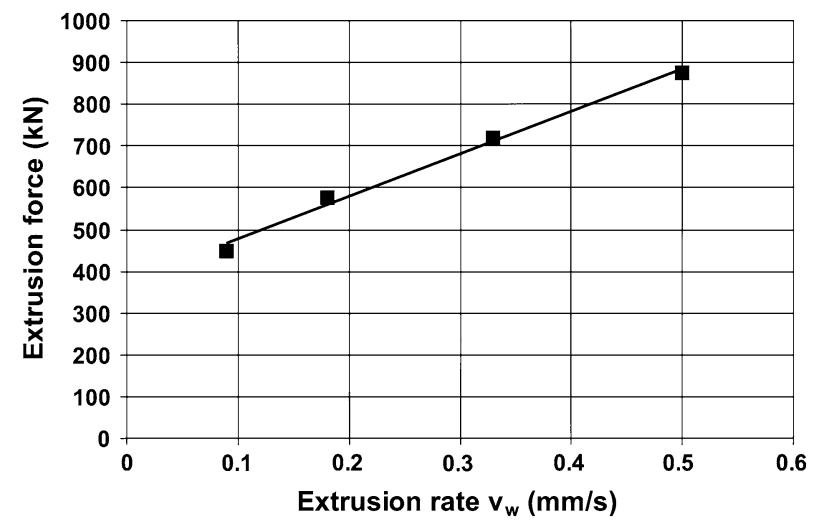

Fig. 9-Dependence of maximal extrusion force on extrusion rate $v_{w}$ of aluminum $\left(\lambda=100, f=5 \mathrm{~Hz}, T_{o}=293 \mathrm{~K}\left(20^{\circ} \mathrm{C}\right)\right)$.

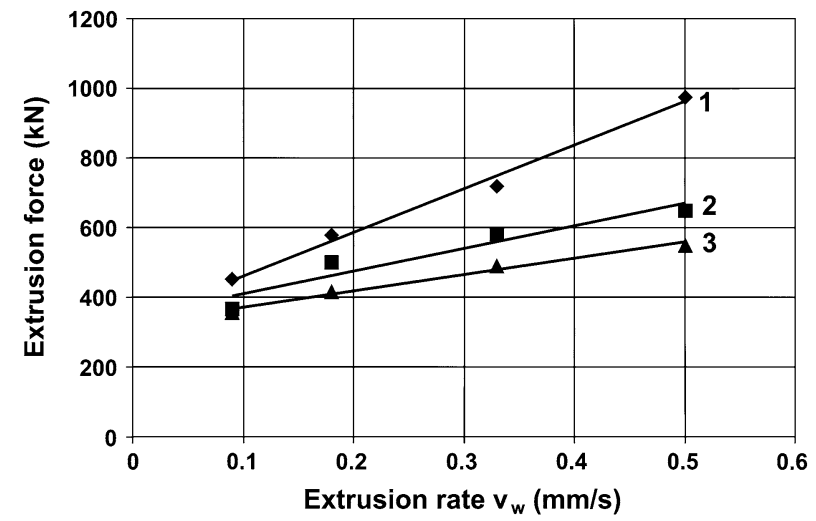

Fig. 10-Dependence of maximal extrusion force on extrusion rate $v_{w}$ of aluminum at different temperatures $(\lambda=100, f=5 \mathrm{~Hz})$. Values of maximal forces were calculated as averages from the three measurements. Note: curve 1 corresponds to $T_{o}=293 \mathrm{~K}\left(20^{\circ} \mathrm{C}\right)$, curve 2 to $T_{o}=373 \mathrm{~K}\left(100{ }^{\circ} \mathrm{C}\right)$, and curve 3 to $T_{o}=573 \mathrm{~K}$ $\left(300{ }^{\circ} \mathrm{C}\right)$.

rate. These should prevent "acceleration" of the process, giving it a characteristic of stationary course. Figure 18 presents an example documenting such effect. Limiting of the extrusion force to $900 \mathrm{kN}$ at an oscillation 


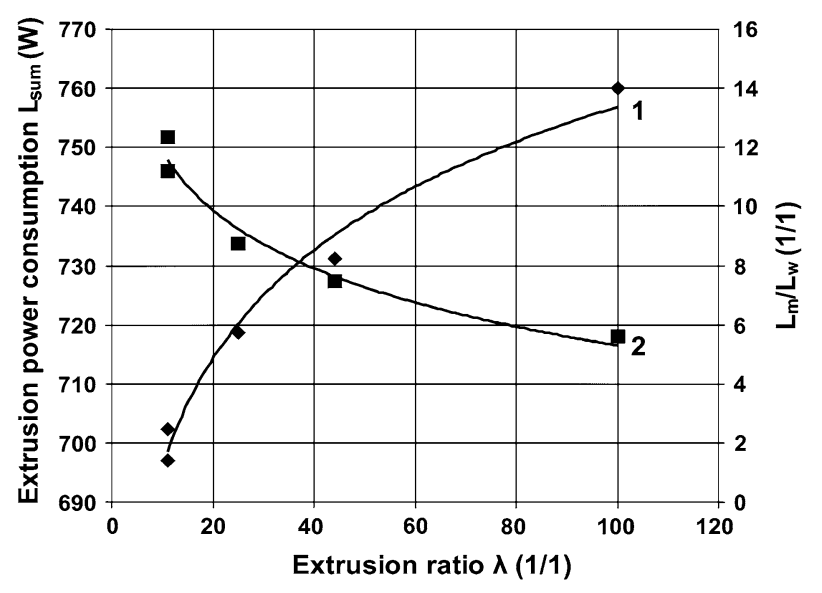

Fig. 11-Dependence of maximal power consumption of the KOBO extrusion process of 7075 alloy $L_{m}+L_{w}$ (1) and the ratio $L_{m} L_{w}$ (2) on extrusion ratio $\lambda$, at room temperature.

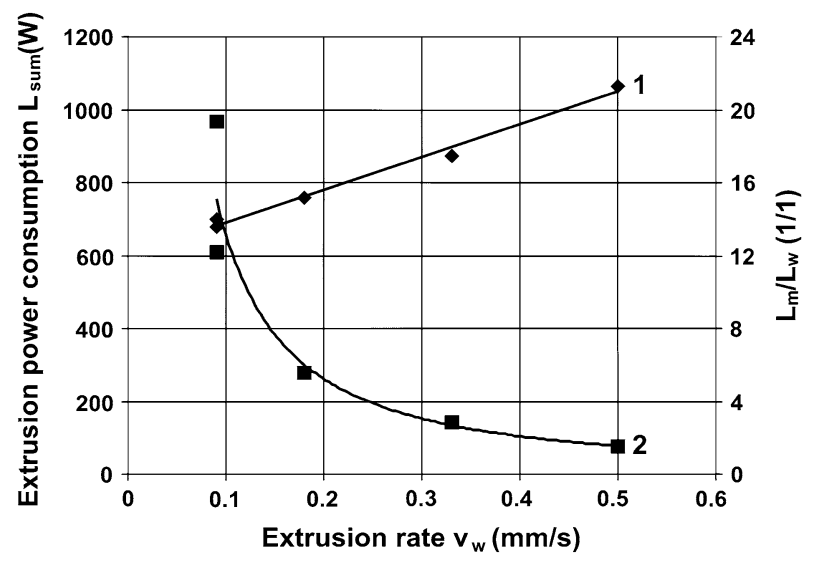

Fig. 12-Dependence of maximal power consumption of the KOBO extrusion process of aluminum $L_{m}+L_{w}$ (1) and the ratio $L_{m} L_{w}$ (2) on extrusion rate $v_{w}$, at room temperature.

frequency of $3 \mathrm{~Hz}$ ensured a stable process course at a true extrusion rate of $0.3 \mathrm{~mm} / \mathrm{s}$ (at an assigned punch speed of $0.5 \mathrm{~mm} / \mathrm{s}$ ). However, these conditions are disadvantageous from an energy point of view (work per volume unit $\left(L_{w}+L_{m}\right) /\left(A_{o} \cdot v_{w}\right)=2.8 \mathrm{~J} / \mathrm{mm}^{3}$ is almost twice as high as the minimal one obtained within the frames of the present study (Figures 14 and 15)).

Increasing torsion frequency leads to the lowering of power consumption and an increase of extrusion rate. Figure 19 illustrates that in conditions of limited press load to $750 \mathrm{kN}$, at die oscillation frequency of $2 \mathrm{~Hz}$, the true extrusion rate stabilizes at the level of $0.07 \mathrm{~mm} / \mathrm{s}$, while the torsion force equals $6 \mathrm{kN}$. The increase of frequency to $5 \mathrm{~Hz}$ leads to a decrease of torsion force to a level of $2 \mathrm{kN}$ and an increase of true extrusion rate to $5.0 \mathrm{~mm} / \mathrm{s}$. Consequently, the extrusion work, calculated per unit volume of metal, is reduced from 6.46 to $1.28 \mathrm{~J} / \mathrm{mm}^{3}$. Thus, higher torsion frequency reduces the energy consumption of the process, whereas at increased torsion frequency, the process is only temporarily

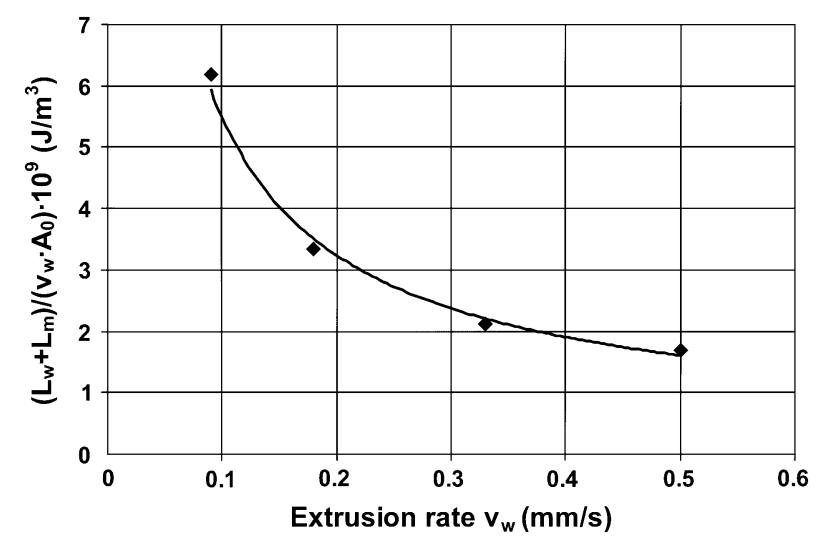

Fig. 13-Dependence of energy-consumption parameter $\left(L_{w}+L_{m}\right) /$ $\left(v_{w} \cdot A_{o}\right)$ on extrusion rate of 7075 alloy $\left(\lambda=100, T_{o}=293 \mathrm{~K}\right.$ $\left.\left(20^{\circ} \mathrm{C}\right)\right)$.

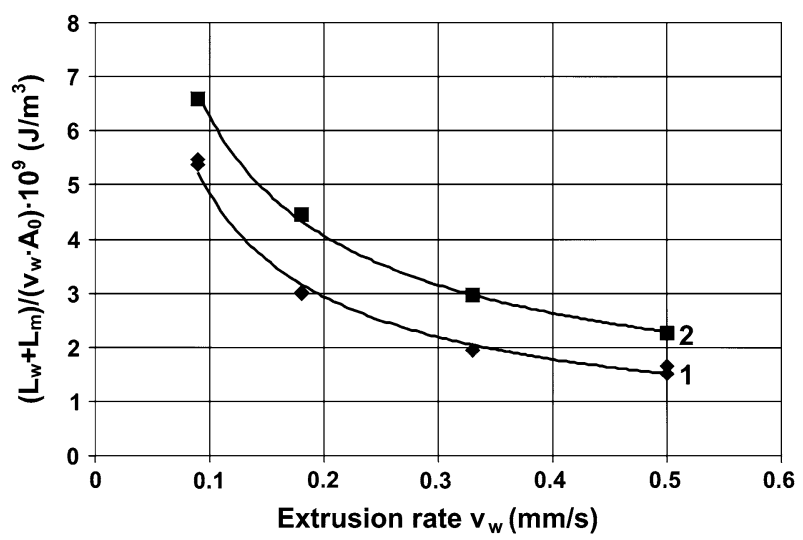

Fig. 14-Dependence of energy-consumption parameter $\left(L_{w}+L_{m}\right) /$ $\left(v_{w} \cdot A_{o}\right)$ on extrusion rate of aluminum subjected to different extrusion ratios $\lambda$, at room temperature. Note: curve 1 corresponds to $\lambda=100$ and curve 2 to $\lambda=256$.

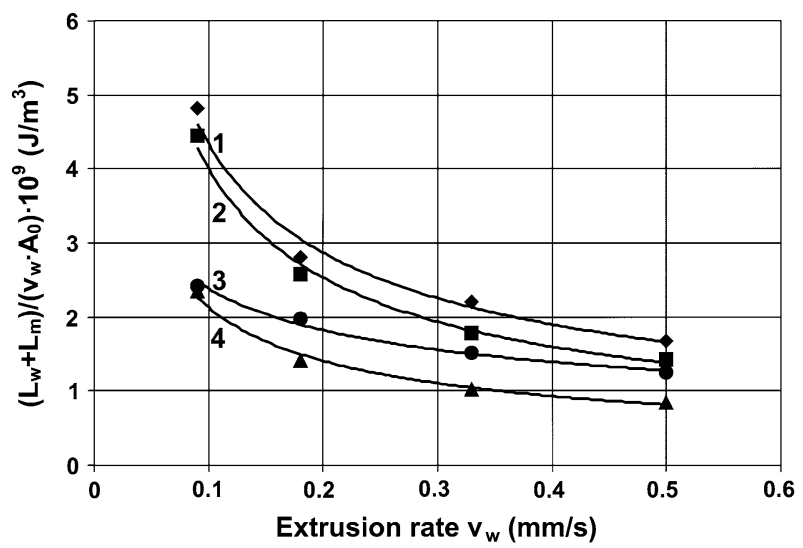

Fig. 15-Dependence of energy-consumption parameter $\left(L_{w}+L_{m}\right) /$ $\left(v_{w} \cdot A_{o}\right)$ on extrusion rate $v_{w}$ of aluminum subjected to extrusion ratio $\lambda=100$ at different temperatures. Note: curve 1 corresponds to $T_{o}=293 \mathrm{~K}\left(20^{\circ} \mathrm{C}\right)$, curve 2 to $T_{o}=373 \mathrm{~K}\left(100^{\circ} \mathrm{C}\right)$, curve 3 to $T_{o}=473 \mathrm{~K}\left(200{ }^{\circ} \mathrm{C}\right)$, and curve 4 to $T_{o}=573 \mathrm{~K}\left(300{ }^{\circ} \mathrm{C}\right)$. 


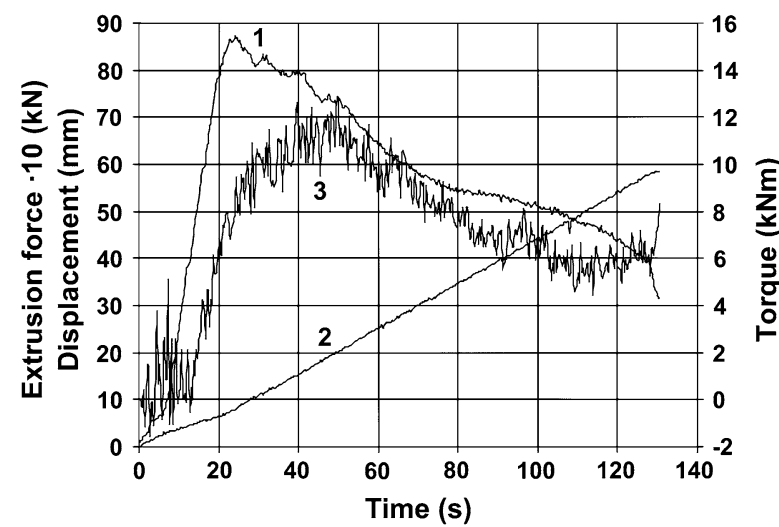

(a)

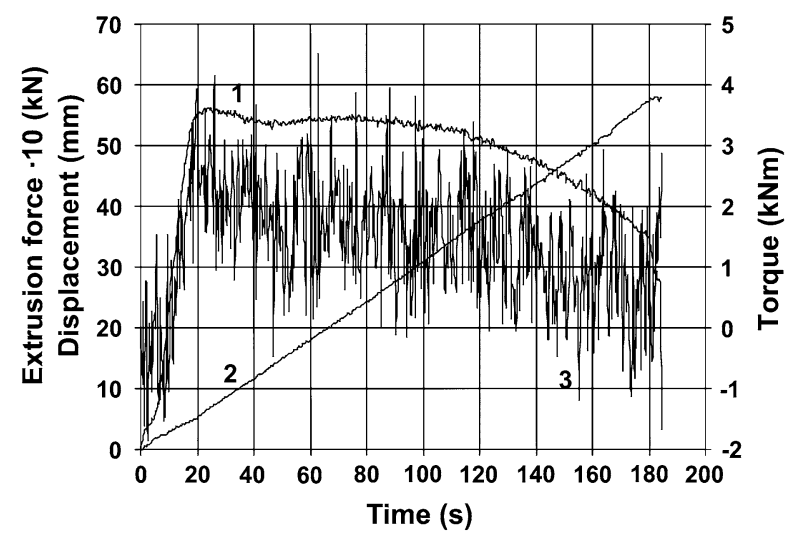

(c)

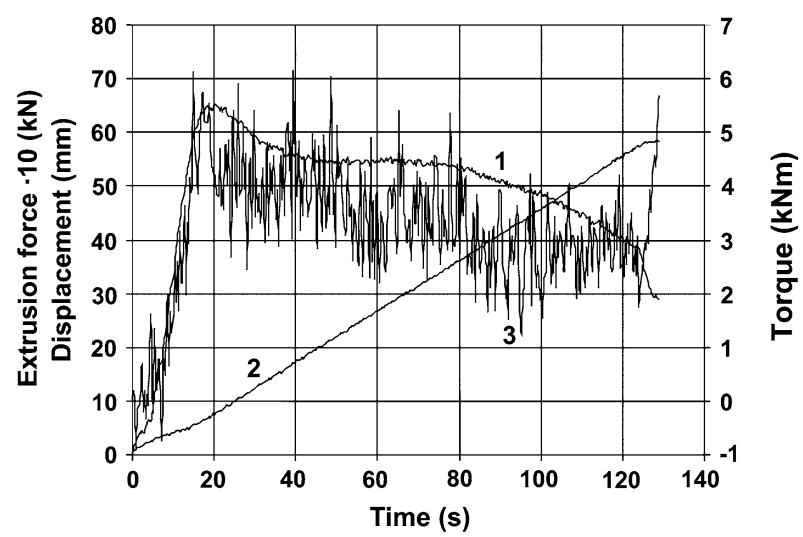

(b)

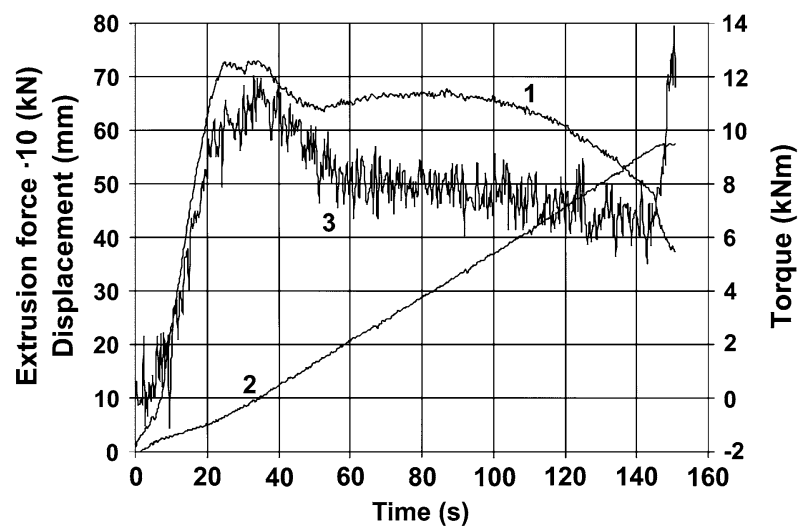

(d)

Fig. 16-Extrusion characteristics for aluminum $\left(\lambda=100, T=293 \mathrm{~K}\left(20^{\circ} \mathrm{C}\right)\right.$, angle $\left.\pm 8 \mathrm{deg}\right)$, showing the influence of extrusion rate and torsion frequency on extrusion force and torsional moment: (a) $v_{w}=0.5 \mathrm{~mm} / \mathrm{s}$, frequency $5 \mathrm{~Hz} ;(b) v_{w}=0.33 \mathrm{~mm} / \mathrm{s}$, frequency $5 \mathrm{~Hz}$; (c) $v_{w}=0.5 \mathrm{~mm} / \mathrm{s}$, frequency $8 \mathrm{~Hz}$; and $(d) v_{w}=0,33 \mathrm{~mm} / \mathrm{s}$, frequency $8 \mathrm{~Hz}$ (true extrusion rate is verified by the slope of punch displacement in time). Note: curve 1 corresponds to extrusion force $\mathrm{kN}$, curve 2 to displacement $\mathrm{mm}$, and curve 3 to torque $\mathrm{kNm}$.

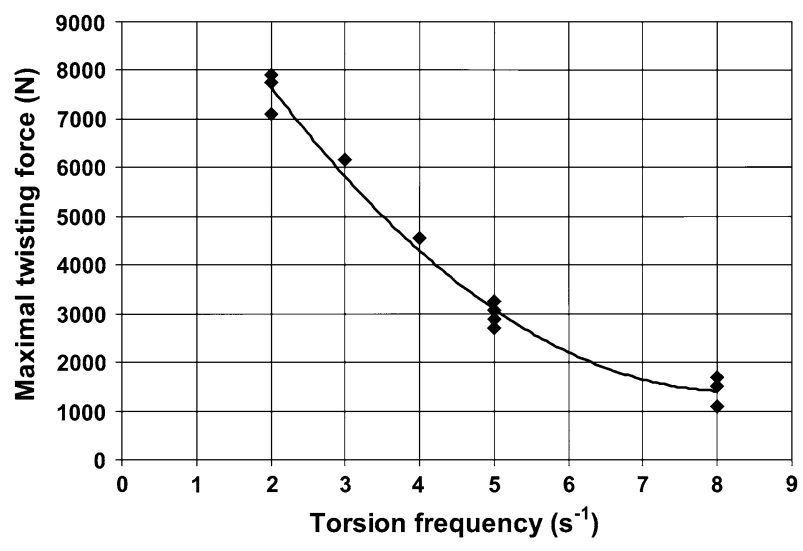

Fig. 17-Dependence of maximal torque on torsion frequency for aluminum subjected to extrusion ratio of $\lambda=100$ at fixed extrusion rate $v_{w}=0.05 \mathrm{~mm} / \mathrm{s}$ at $T=293 \mathrm{~K}\left(20^{\circ} \mathrm{C}\right.$ ) (at frequencies lower than $5 \mathrm{~Hz}$, true extrusion rates varied from $0.07 \mathrm{~mm} / \mathrm{s}$ at $f=2 \mathrm{~Hz}$ to $0.23 \mathrm{~mm} / \mathrm{s}$ at $f=4 \mathrm{~Hz}$ ).

stationary, when both extrusion force and torsion force are maintained at the same level for about 100 seconds. Besides, as shown in Figure 20, the reduction of extrusion force to about $900 \mathrm{kN}$, at a torsion frequency of $2 \mathrm{~Hz}$, results in reaching the state of stationary

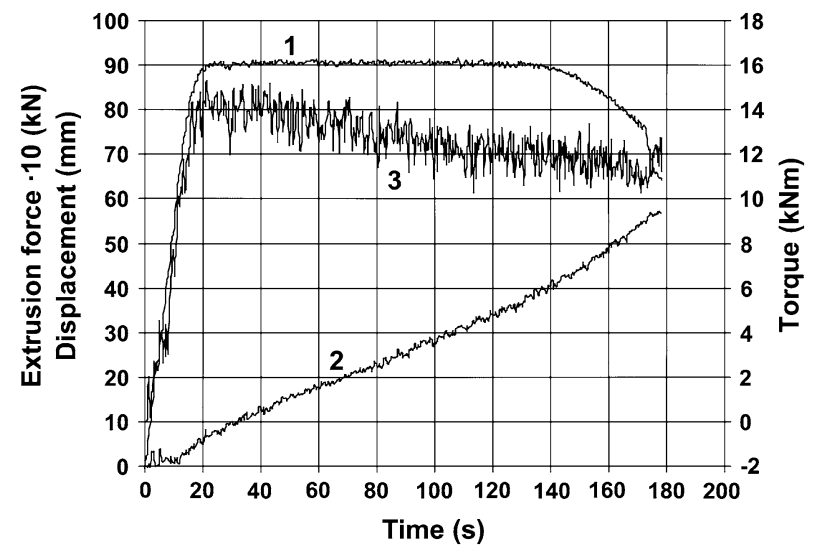

Fig. 18- Characteristics of the KOBO extrusion of aluminum at the temperature of $293 \mathrm{~K}\left(20{ }^{\circ} \mathrm{C}\right)$ with reduced to $900 \mathrm{kN}$ maximal force of punch $(f=3 \mathrm{~Hz}, \lambda=100)$. True extrusion rate equals $0.3 \mathrm{~mm} / \mathrm{s}$. Note: curve 1 corresponds to extrusion force $\mathrm{kN}$, curve 2 to displacement $\mathrm{mm}$, and curve 3 to torque $\mathrm{kNm}$.

process at an extrusion rate (punch speed) of $0.04 \mathrm{~mm} / \mathrm{s}$. Torsion force is maintained at that time at a level of $7.2 \mathrm{kN}$. The increase of frequency to $8 \mathrm{~Hz}$ results in a decrease of torsion force to the level of $1.6 \mathrm{kN}$ and monotone decrease of extrusion force. 
The role of friction forces that occur during the extrusion with the KOBO method remains open. Even though the profile of force-distance curves in the condition of the stationary process suggests a limited role of friction between the metal and the walls of the container, the magnitude of metal compressing stress

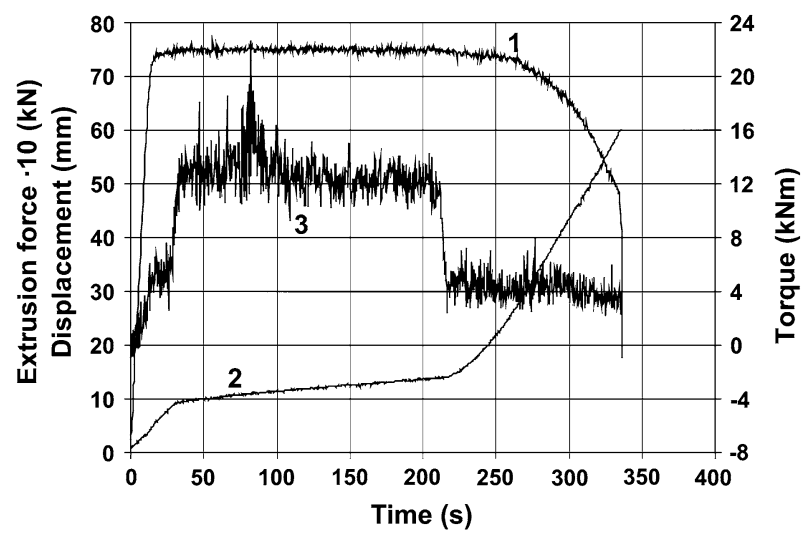

Fig. 19- Characteristics of the KOBO extrusion of aluminum at the temperature of $293 \mathrm{~K}\left(20^{\circ} \mathrm{C}\right)$ with reduction to $750 \mathrm{kN}$ maximal force of punch $(f=2$ and $5 \mathrm{~Hz}, \lambda=100)$. True extrusion rate equals $0.07 \mathrm{~mm} / \mathrm{s}$. Note: curve 1 corresponds to extrusion force $\mathrm{kN}$, curve 2 to displacement $\mathrm{mm}$, and curve 3 to torque $\mathrm{kNm}$.

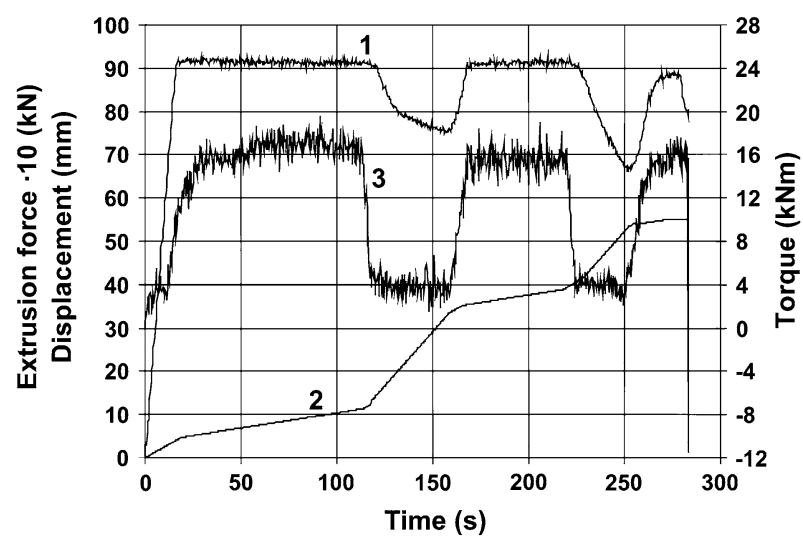

Fig. 20 - Characteristics of the KOBO extrusion of aluminum at the temperature of $293 \mathrm{~K}\left(20^{\circ} \mathrm{C}\right)$ with reduction to $900 \mathrm{kN}$ maximal force of punch $(f=2$ and $8 \mathrm{~Hz}, \lambda=100)$. True extrusion rate equals $0.04 \mathrm{~mm} / \mathrm{s}$. Note: curve 1 corresponds to extrusion force $\mathrm{kN}$, curve 2 to displacement $\mathrm{mm}$, and curve 3 to torque $\mathrm{kNm}$. inside the container exceeds by a few times the aluminum yield point even at room temperature (already at an extrusion force level of $500 \mathrm{kN}$, the stress equals $400 \mathrm{MPa}$ ). At such high compressing stress, the "upsetting" of metal in the container is unavoidable and the decrease of yield point as a result of metal heating during extrusion may even intensify that effect. This would explain the appearance of a "hump" in force change curve, which is fostered by high extrusion force and lack of lubricant (the extrusions were "dry" performed).

In light of the preceding experimental facts, metal extrusion using a press with oscillating die comes out as a process in which mutual relations between extrusion force, torque, oscillation frequency, and extrusion rate determine its energy consumption and stability. The results show that the factors fostering the reduction of the energy cost of the process are the increase of extrusion rate (and indirectly increase of extrusion ratio $\lambda$ ) and the increase of oscillation frequency of the die. Running the process at higher temperatures obviously leads to a decrease of extrusion force and torsion force and, consequently, of extrusion work. However, then, the full energy balance must include the energy spent on heating the metal prior to extrusion. An important advantage of the $\mathrm{KOBO}$ method is that the extrusion force reduction is possible without preheating the material.

Unfortunately, due to the limited maximum pressure of the owned press, comparison of the energy expenditure in the process between the KOBO method and conventional extrusion carried out under conditions of immobilized die was not possible for most planned variants of the process. This study only managed to compare the energy consumption of the two methods, when the process was carried out at higher temperatures. And so, at the temperature of $472 \mathrm{~K}\left(200{ }^{\circ} \mathrm{C}\right)$, a 35 -mm-long aluminum billet was conventionally extruded at maximal force possible to obtain for this press $(1000 \mathrm{kN})$, with extrusion ratio $\lambda=11$ and rate of $0.5 \mathrm{~mm} / \mathrm{s}$. At a temperature of $573 \mathrm{~K}\left(300{ }^{\circ} \mathrm{C}\right)$, it was possible to extrude with the same method the billet $60-\mathrm{mm}$ long with extrusion ratio of $\lambda=45$ at true extrusion rate of $0.43 \mathrm{~mm} / \mathrm{s}$, and even extrusion ratio of $\lambda=100$, but at lower rate $(0.06 \mathrm{~mm} / \mathrm{s})$. The results of estimation of total extrusion work of aluminum billets with different length are presented in Table II.

Experimental data in Table II show that the metal extrusion with the KOBO method using a press with

Table II. Total Extrusion Work of Aluminum Billets with Different Methods

\begin{tabular}{|c|c|c|c|c|c|}
\hline \multirow[b]{2}{*}{ Temperature $\left[\mathrm{K}\left({ }^{\circ} \mathrm{C}\right)\right]$} & \multirow{2}{*}{$\begin{array}{c}\text { Processing } \\
\text { Degree } \lambda\end{array}$} & \multirow{2}{*}{$\begin{array}{c}\text { Extrusion } \\
\text { Rate }(\mathrm{mm} / \mathrm{s})\end{array}$} & \multirow{2}{*}{$\begin{array}{c}\text { Billet } \\
\text { Length }(\mathrm{mm})\end{array}$} & \multicolumn{2}{|c|}{ Total Extrusion Work (kJ) } \\
\hline & & & & Conventionally & KOBO $( \pm 8 \mathrm{Deg}, 5 \mathrm{~Hz})$ \\
\hline $473(200)$ & 11 & 0.50 & 35 & 22.0 & 21.0 \\
\hline \multirow[t]{5}{*}{$573(300)$} & 45 & 0.43 & 60 & 46.8 & \multirow{3}{*}{38.5} \\
\hline & \multirow{4}{*}{100} & 0.50 & & & \\
\hline & & 0.06 & 60 & 64.2 & \\
\hline & & 0.09 & & & 145.8 \\
\hline & & 0.50 & & & 66.0 \\
\hline
\end{tabular}


oscillating die not only allows for metal forming at low temperature with high extrusion ratio, but is an energysaving process as well. Already at an extrusion ratio of $\lambda=45$, a positive energy balance is clearly visible. On the other hand, total extrusion work of the process is strictly dependent on its rate-frequency parameters. Table II clearly presents this dependence, if one compares the total extrusion work of a 60-mm-long sample with the extrusion ratio of $\lambda=100$ at a temperature of $573 \mathrm{~K}\left(300^{\circ} \mathrm{C}\right)$. This shows that almost the same work is needed to extrude the metal with the KOBO method as during the conventional process; however, the extrusion rate of the first process is almost 10 times higher.

A decrease of extrusion rate with maintained torsion frequency in the $\mathrm{KOBO}$ method makes the process strongly energy consuming, because then the fraction of torsion work increases. Start: Decrease of oscillation frequency is not the way to reduce torsion work, which distinctly suggests that there is a structural cause of such behavior. Its source should be looked for among the mechanisms present during large deformations realized in conditions of variable strain scheme (cyclic change of deformation path).

\section{STRUCTURAL PATTERN OF THE KOBO EXTRUSION PROCESS}

The effect of the strong reduction of force needed for plastic deformation of metal at the moment of change of strain scheme by introduction of the cyclically variable "transverse" deformation during extrusion generated interest in a search for the reason for such behavior. In particular, the increase of metal temperature as a result of additional plastic deformation (reverse torsion of the material) may seem to be its most probable cause. However, the results presented in the previous sections show that the extrusion work of the KOBO method is lower than the work needed for conventional extrusion at the same rate parameters of the process. Therefore, one should conclude that extrusion work dissipation in the KOBO method should result in lower temperature gain, which makes the connection of a strong reduction of extrusion force in the KOBO method with heat effect doubtful. Of course, the increase of metal temperature during extrusion is unavoidable, especially at high extrusion ratio $\lambda$, and it rises during extrusion ("cold" at the beginning and "hot" at the end). Results of the pyrometric measurements of the butt of the 7075 alloy extruded at different temperatures at the rate of $0.18 \mathrm{~mm} / \mathrm{s}$ are presented in Table III.

The measurements were carried out after retracting the container from a die, which means that, in relation to the actual temperature, they may be burdened with an error resulting from the cooling metal for the period of a few seconds between the end of the process and measurement. These demonstrate, though, that the effect of heating the metal during extrusion is relatively small. In particular, at the highest extrusion ratio $\lambda=100$ and adverse conditions, from the extrusion rate point of view, the temperature increase of cold metal is of the order of a hundred and a few dozen
Table III. Temperature of 7075 Alloy (and the Container) Extruded by the KOBO Method $( \pm 8 \mathrm{Deg}, 5 \mathrm{~Hz})$

\begin{tabular}{|c|c|c|c|}
\hline $\begin{array}{l}\text { Initial } \\
\text { Temperature } \\
\text { of Billet and } \\
\text { Container } \\
{\left[\mathrm{K}\left({ }^{\circ} \mathrm{C}\right)\right]}\end{array}$ & $\begin{array}{c}\text { Extrusion } \\
\text { Ratio } \lambda\end{array}$ & $\begin{array}{l}\text { Temperature } \\
\text { of Extrusion } \\
\text { Butt }\left[\mathrm{K}\left({ }^{\circ} \mathrm{C}\right)\right]\end{array}$ & $\begin{array}{c}\text { End } \\
\text { Temperature } \\
\text { of the Container } \\
{\left[\mathrm{K}\left({ }^{\circ} \mathrm{C}\right)\right]}\end{array}$ \\
\hline \multirow[t]{4}{*}{293 (20) } & 11 & $108(381)$ & $31(304)$ \\
\hline & 25 & $138(411)$ & $39(312)$ \\
\hline & 45 & $150(423)$ & $41(314)$ \\
\hline & 100 & $160(433)$ & 45 (318) \\
\hline \multirow[t]{4}{*}{$393(120)$} & 11 & $120(393)$ & $123(396)$ \\
\hline & 25 & $170(443)$ & $122(395)$ \\
\hline & 45 & $156(429)$ & $121(394)$ \\
\hline & 100 & $237(510)$ & $120(393)$ \\
\hline \multirow[t]{4}{*}{$523(250)$} & 11 & $293(566)$ & $248(521)$ \\
\hline & 25 & $320(593)$ & $249(522)$ \\
\hline & 45 & $314(587)$ & $245(518)$ \\
\hline & 100 & $332(605)$ & $250(523)$ \\
\hline \multirow[t]{4}{*}{$673(400)$} & 11 & $391(664)$ & $400(673)$ \\
\hline & 25 & $412(685)$ & 396 (669) \\
\hline & 45 & $431(704)$ & $396(669)$ \\
\hline & 100 & $452(725)$ & $402(675)$ \\
\hline
\end{tabular}

degrees. Thus, the process is running both at the beginning and at the end in terms of cold plastic deformation. Indeed, the metallographic pictures presented in Figure 21 of wire structure of 7075 alloy extruded with the extrusion ratio $\lambda=100$, and revealed by etching using Keller's reagent, show recrystallization of the sample extruded at the temperature of $673 \mathrm{~K}$ $\left(400{ }^{\circ} \mathrm{C}\right.$ ) only (Figure $\left.21(\mathrm{~d})\right)$. At lower temperatures, extrusion leads to the creation of a typical large deformation band structure, visible on the longitudinal cross sections, which is consistent with the earlier statement that alloy was extruded at a low temperature, which does not lead to recrystallization.

It is also important to note a significant difference between plastic deformation of preheated metal and the deformation process as a result of which, due to work dissipation, the increase of metal temperature occurs. The largest temperature increase is expected to be in the "end" of the deformation zone, i.e., in the die nib, and thus in the area where even the most intensified structural changes have no impact on the deformation resistance of extruded metal any more. Accordingly, the questions on how the deformation zone is formed and what the mechanism of deformation work dissipation is are the keys to explaining the observed force-energy effects of the process. Comparatively, Figure 22 presents aluminum "flow images" in the deformation zone formed in conditions of the extrusion of samples through an immobilized die (continuous lines) and the oscillating die (interrupted lines) for $2 \mathrm{deg}$ of processing, $\lambda=3.5$ and 25. ${ }^{[53]}$ The lines in the figure reflect the position of "markers" of copper (thin film separating parts of the sample) in extruded metal and show a very strong effect of torsion on the width of the deformation zone and the characteristics of metal flow. This effect becomes apparent particularly well with the increase of the extrusion ratio. With the reduction of the sample 


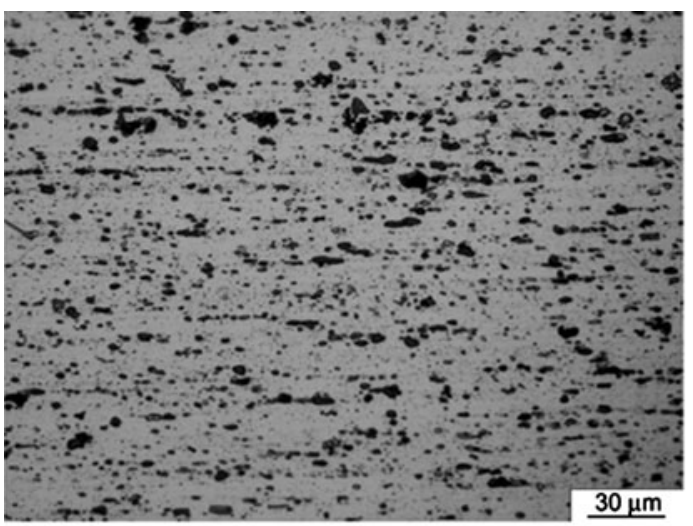

(a)

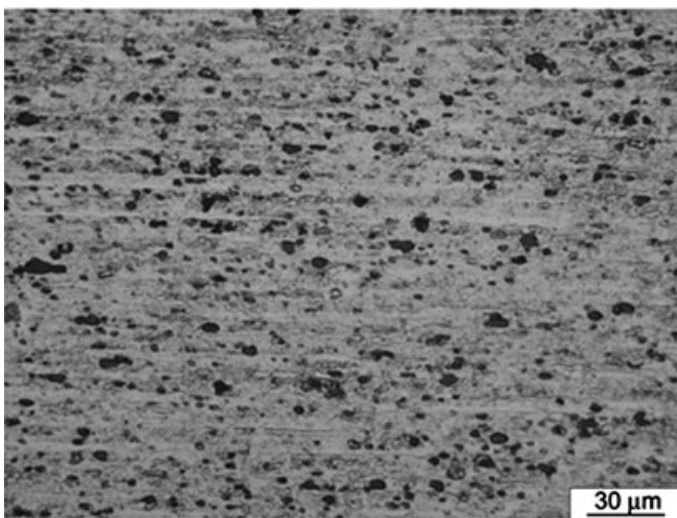

(c)

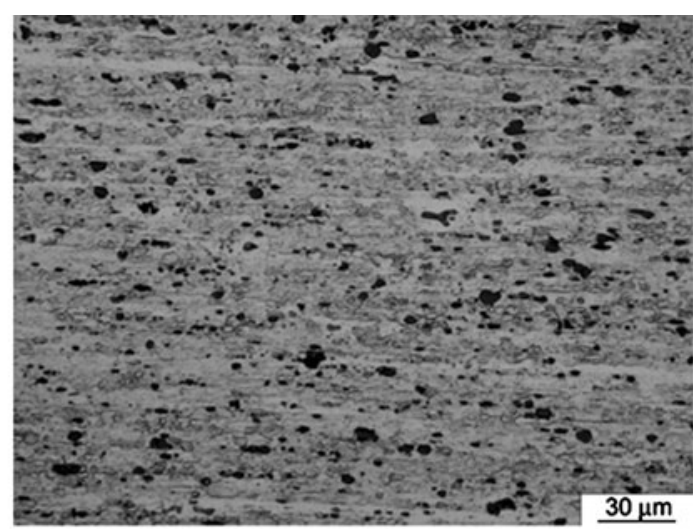

(b)

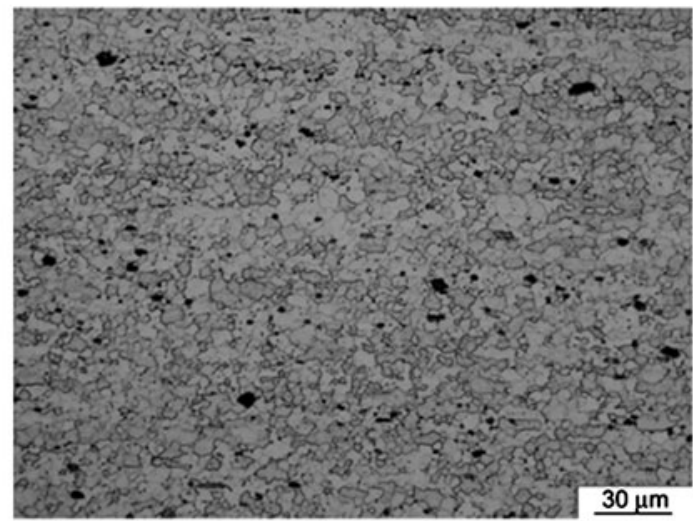

(d)

Fig. 21 - Structures of wire made of 7075 alloy obtained in the $\mathrm{KOBO}$ extrusion process at different temperatures $(\lambda=100, f=5 \mathrm{~Hz})$ : (a) $T_{o}=293 \mathrm{~K}\left(20^{\circ} \mathrm{C}\right),(b) T_{o}=373 \mathrm{~K}\left(100{ }^{\circ} \mathrm{C}\right),(c) T_{o}=473 \mathrm{~K}\left(200{ }^{\circ} \mathrm{C}\right)$, and $(d) T_{o}=573 \mathrm{~K}\left(300{ }^{\circ} \mathrm{C}\right)$.

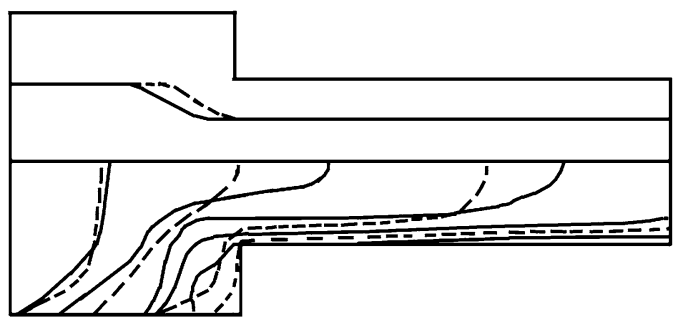

(a)

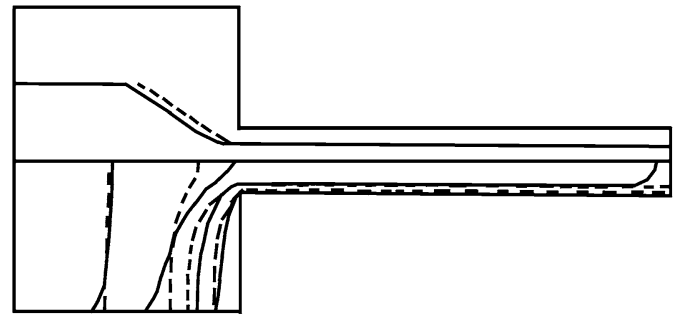

(b)

Fig. 22-Images of deformation zone represented by placed "markers" of copper foil. Continuous lines show marker orientations in the butt of aluminum extruded through an immobilized die, while an interrupted line shows through an oscillating die (the KOBO) for different extrusion ratios $\lambda:(a) \lambda=3.5, \alpha \pm 11 \mathrm{deg}$ and $(b) \lambda=25, \alpha \pm 11 \mathrm{deg}$.

cross section $(\lambda=25)$, the flow zone becomes very narrow and the character of flow changes from radialaxial to radial (flow perpendicular to the direction of extrusion). Structural observations of the butt being the rest of the billet of the 7075 alloy confirm the conclusion about strong narrowing - to approximately $2 \mathrm{~mm}$ - of the deformation zone during extrusion with the KOBO method and the predominant role of radial flow (Figure 23).

Study of the structure of the aluminum butt (Figure 24) provided additional, important, and more detailed information about the way of flow in the deformation zone. Dominant radial flow is revealed by the strong elongation of etched structure elements (grains, subgrains) in a narrow zone of radial width of the order of $1 / 2$ to $2 / 3$ the radius of the sample (as in the areas marked in Figure 24 with numbers 1 and 2). In the peripheral parts of the zone, there is a share of "axial" flow causing curving of structure elements. Also present are a strong structure gradient in the deformation zone and a particularly strong refinement of the structure in the outer layers reaching deep into the sample up to 


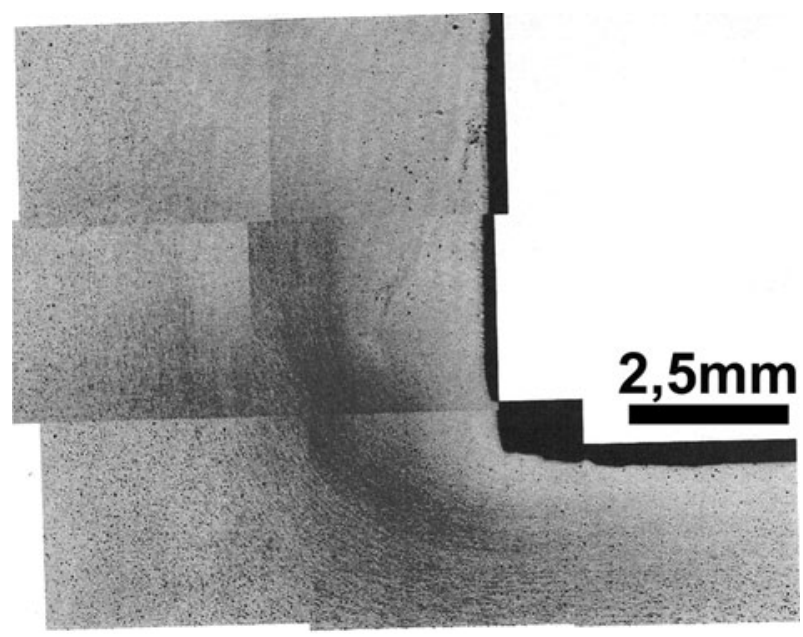

Fig. 23-Structure of deformation zone of 7075 alloy extruded at room temperature by the KOBO method with extrusion ratio $\lambda=100(\alpha= \pm 8 \mathrm{deg}, f=5 \mathrm{~Hz})$.

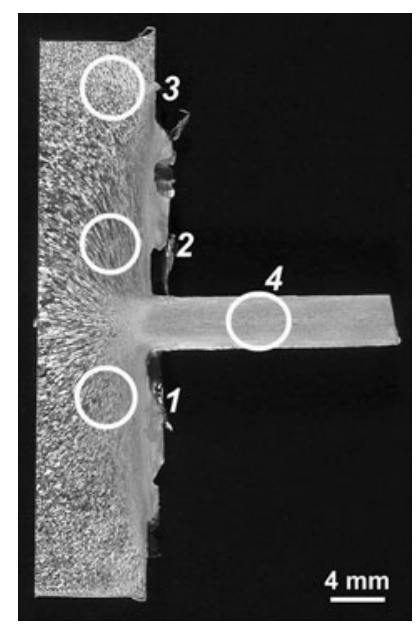

Fig. 24-Structure of deformation zone of aluminum extruded at room temperature by the KOBO method with extrusion ratio $\lambda=100(\alpha= \pm 8 \mathrm{deg}, f=5 \mathrm{~Hz})$. There are marked zones of plastic flow being analyzed in the present work.

about 20 pct of the length of its radius (the area marked with number 3 ).

Microstructures of samples taken from areas marked in Figure 24 revealed with the transmission electron microscopy technique (Figures 25 through 29) that the gradient of the structure concern is due to the difference in dislocation density between particular areas. In the external deformation zone (area 3), there are observed dislocation tangles forming a cellular structure with a number of dislocations inside the cells (Figure 25). The image of a typical microstructure for the radial flow zone (areas " 1 " and " 2 ") is shown in subsequent figures (Figures 26 and 27). It is particularly significant that, within the area of radial flow, there is practically no dislocation inside strongly elongated subgrains (blocks). It is therefore concluded that radial flow is accompanied

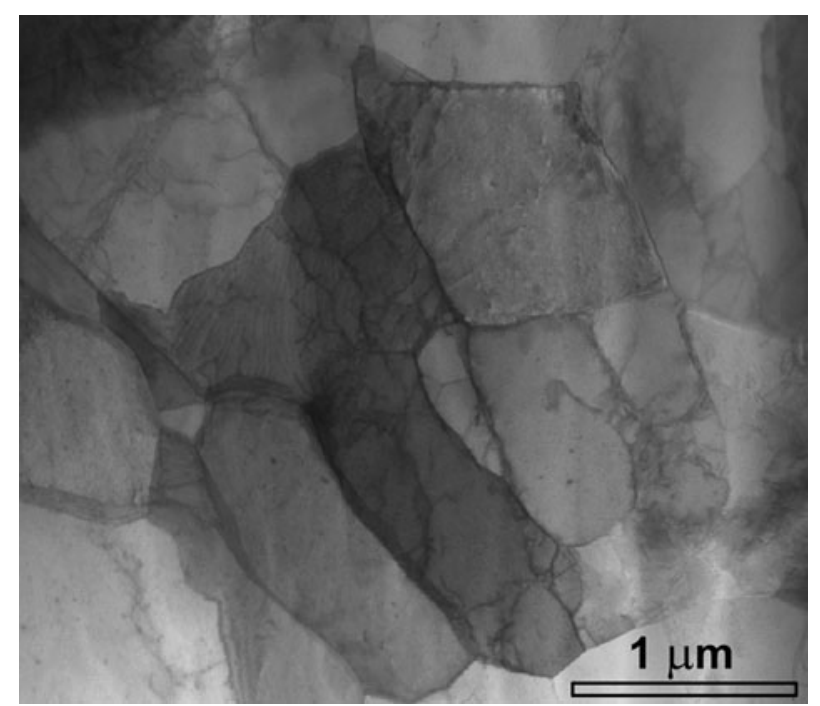

Fig. 25-Microstructure of aluminum as in Fig. 24 in the outer area of the butt (place marked 3).

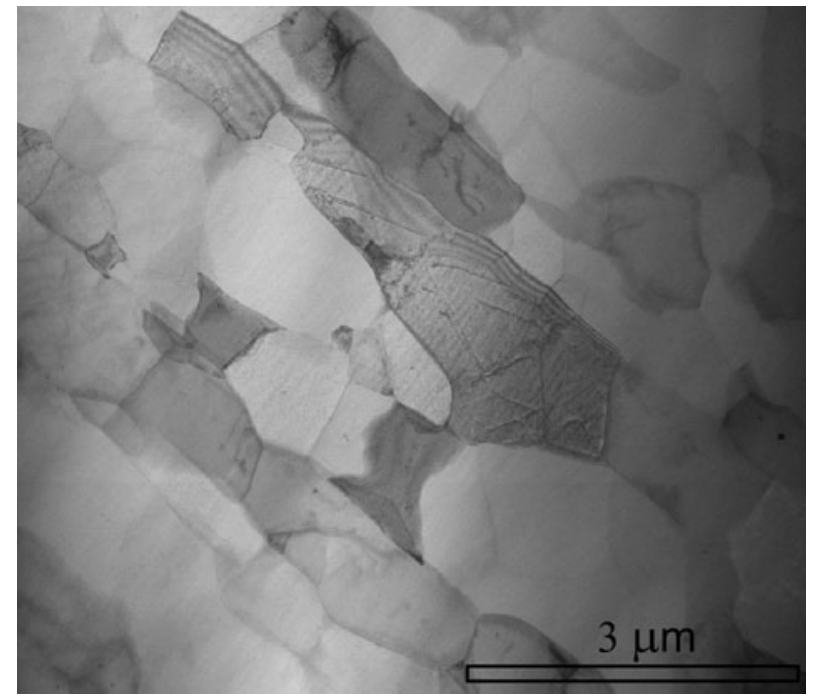

Fig. 26-Microstructure of aluminum as in Fig. 24 within the area of radial flow (place marked 1).

by very intense dislocation climb, which leads to the dislocations annihilation, or "pushes" the dislocations from inside subgrains to the dislocation walls, transforming them into low-angle boundaries (Figure 28). The process is strongly dissipative (changes the stored deformation work into heat) and has a character of the diffusion process (dislocation climb, mass transport). Figure 29 shows that the structure of subgrains formed in the radial deformation zone is maintained in the product.

A natural consequence of plastic torsion of the material is generation of the structure gradient. In the outer layer, in one full cycle of torsion (from +8 to $-8 \mathrm{deg}$ ), by the zone with a diameter of $40 \mathrm{~mm}$ and a width estimated at $2 \mathrm{~mm}$, the magnitude of true strain is around 2.8. Of course, the area around the axis of the 


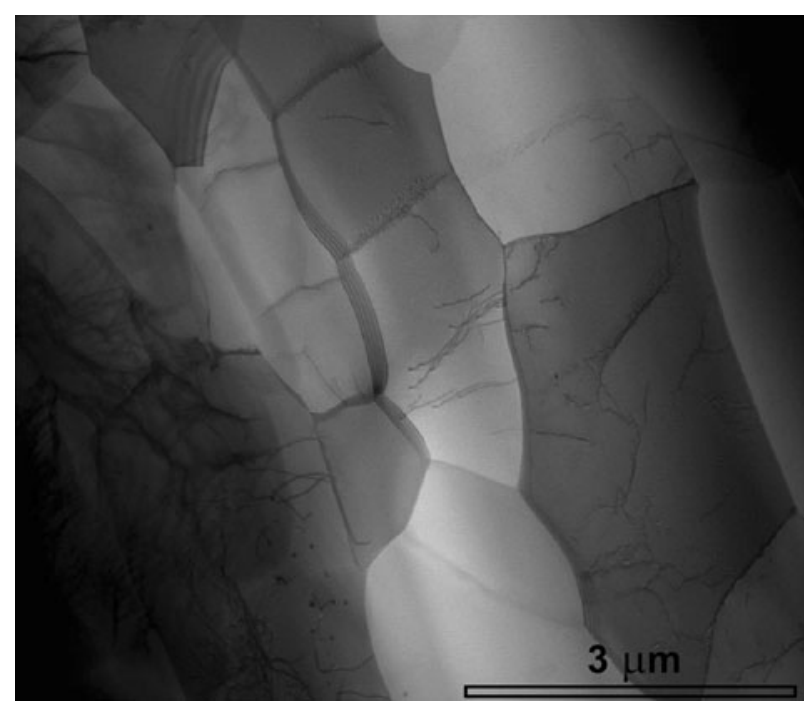

Fig. 27-Microstructure of aluminum as in Fig. 24 within the area of radial flow (place marked 2).

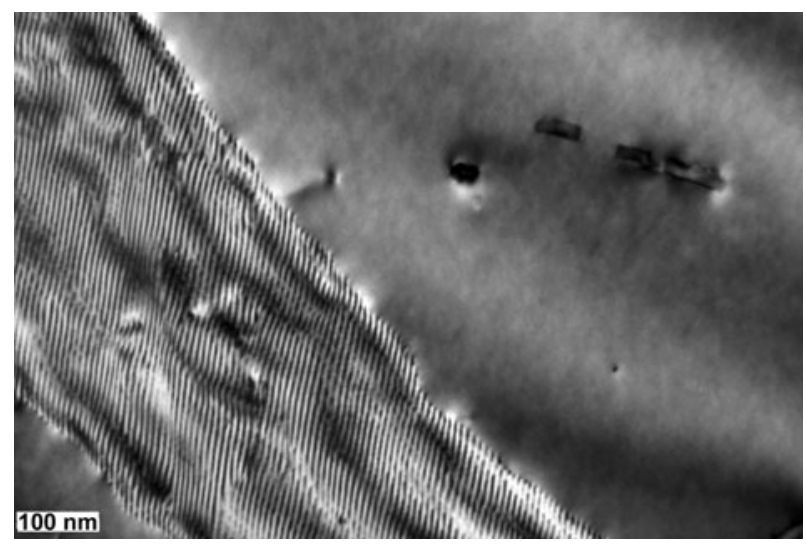

Fig. 28-Picture presenting a fragment of subgrain boundaries within the area of radial flow.

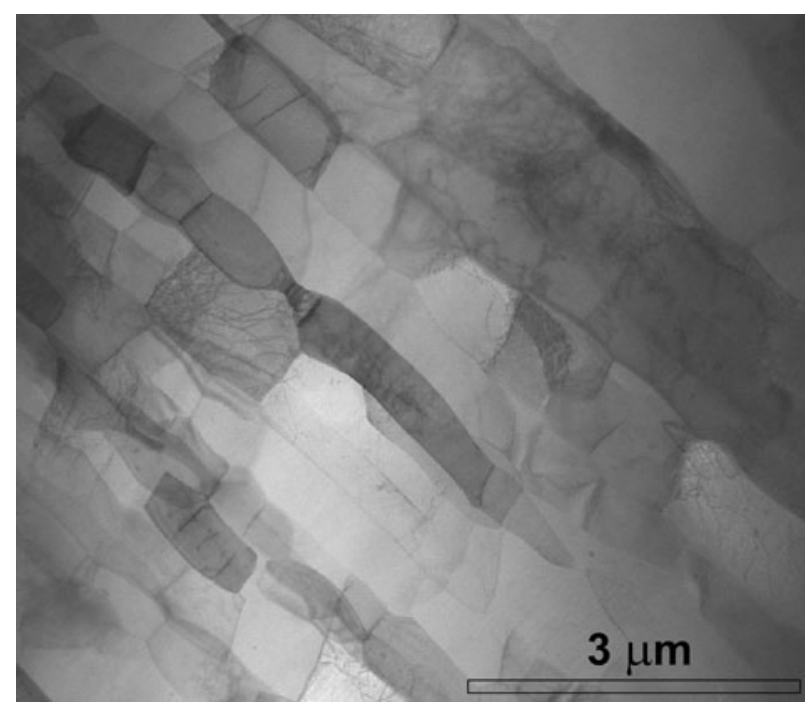

Fig. 29-Microstructure of aluminum as in Fig. 24 in product (place marked 4). sample is not subjected to plastic torsion. Changing the direction of torsion is accompanied by an intensive process of dislocation intersections. On the other hand, formation of point defects (vacancies, self-interstitials) is well explained as an effect of dislocation intersections or due to formation of dipoles by dislocations, which are force to glide in opposite directions. Changing the strain path and, in particular, reversing the plastic flow directions in torsion works toward intensification of these events.

It seems reasonable, therefore, to conclude that die oscillation frequency (torsion of material) is the determinant of the amount of point defects and its increase should enhance this process. The occurrence of diffusing atoms or vacancies stream equalizing the concentration leads to a significant decrease in viscosity of the material, generating an alternative to the dislocation slip mechanism of plastic deformation. The analysis can justify the thesis that the mechanism of metal extrusion by an oscillating die is a process induced by the intensive generation of point defects. However, it is doubtful to consider the possibility of implementing an enormous true strain forced by extrusion process and especially with high true extrusion rate (strain rate), as a result of diffusion phenomena activation only.

\section{PROCESS KINETICS}

The kinetics of the process controlling plastic deformation at a fixed extrusion ratio is characterized by the dependence of strain rate on flow stress and temperature. Quantities identifying the process are the value of an experimentally determined index exponent of a function binding deformation rate with flow stress, structural parameter, i.e., activated volume, and energy of activation.

Under technological process conditions, in which the impact of the tool with plastically formed metal very strongly differentiates the plastic flow stress (yield point of metal) from the deformation resistance measured in the experiment, and the stress state is an inhomogeneous spatial state (compression combined with torsion), the determination of these parameters is possible after the introduction of several assumptions. Hence, it was assumed that the force of friction between the metal and container and the die, within the range of extrusion rates applied during the tests $(0.09$ to $0.5 \mathrm{~mm} / \mathrm{s})$, does not depend on the extrusion rate. In addition, it was also assumed that the pure torsion of metal does not contribute to its flow in the direction of extrusion (axial component). Last, on the basis of the structural observations, it was assumed that the deformation zone has an axial extent of $l_{s}=2 \mathrm{~mm}$. Therefore, according to the relation $\hat{\varepsilon}=v_{w} \cdot \lambda / l_{s}$ (where $v_{w}$ is the extrusion rate and $\lambda$ indicates extrusion ratio), it became possible to define the dependence between the extrusion stress and extrusion rate. The experimentally determined linear dependence of the extrusion force $F_{w}$ on the extrusion rate $v_{w}$ (Figure 10) shows the linear dependence of the stress initiating extrusion process $\left(\sigma_{w}=F_{w} / A_{o}\right)$ on the 
strain rate $\hat{\varepsilon}$. Hence, the function connecting the stress $\sigma_{w}$ with strain rate $\hat{\varepsilon}$ of type

$$
\sigma_{w}=\sigma^{\prime}+\alpha \cdot{ }^{\prime}{ }^{n}
$$

receives a form

$$
\sigma_{w}=\sigma^{\prime}+\eta \cdot \stackrel{\prime}{\varepsilon}
$$

where $\sigma^{\prime}$ and $\eta$ are constants; in particular, $\eta$ corresponds to the viscosity coefficient.

Table IV contains averaged values of function parameters $(l)$ determined for aluminum extruded with the KOBO method $( \pm 8 \mathrm{deg}, 5 \mathrm{~Hz})$ with $\lambda=100$ at different temperatures.

The form of obtained dependency of extrusion stress on strain rate defines the behavior of the material as Newton liquid (index exponent $n=1$ ). In this interpretation of the obtained dependency, the term $\sigma^{\prime}$ is to be treated as a component of stress, of which the source is friction forces. Such a conclusion becomes more probable due to the fact that the value of $\sigma^{\prime}$ is not dependent on the temperature and its average value is about $300 \mathrm{MPa}$. The share of this component in the extrusion force $\left(\sigma^{\prime}\right.$ acts on the surface, $\left.A_{o}=1254 \mathrm{~mm}^{2}\right)$ is of the order of $380 \mathrm{kN}$. It is interesting to note that the force is close to the extrapolation of the extrusion rate $v_{w}=0$ of the relation $F_{w}-v_{w}$ shown in Figure 10. This proves the correctness of the estimation of the width of the deformation zone on the basis of which the strain rate was determined and, consequently, the value of $\sigma^{\prime}$. It is also worth noting that the values of $\eta$ are not burdened with any assumption.

The radial direction of plastic flow of metal in the deformation zone and the low value of the viscosity coefficient lead to the conclusion that the dominant mechanism of deformation possesses characteristic features of the viscous process. This means that the metal in the $\mathrm{KOBO}$ process behaves like a very viscous liquid.

Treating the viscous process as a result of the replacement of body elastic strain by plastic deformation (relaxation), knowing the value of $\eta$, one can define the elementary act of relaxation, i.e., the so-called relaxation time $\tau_{r}$. For an isotropic body, the relaxation time defines the relationship between the viscosity coefficient $\eta$ and the bulk elasticity modulus $G$ in the form

$$
\tau=\eta / 3 \mathrm{G}
$$

Calculated values of relaxation times for aluminum $(G=27,000 \mathrm{MPa})$ are presented in Table V.

\begin{tabular}{|c|c|c|}
\hline $\begin{array}{l}\text { Temperature } \\
T\left[\mathrm{~K}\left({ }^{\circ} \mathrm{C}\right)\right]\end{array}$ & $\begin{array}{c}\text { Parameter } \\
\sigma^{\prime}(\mathrm{Pa})\end{array}$ & Viscosity Coefficient $\eta[\mathrm{Pa} \cdot \mathrm{s}(\mathrm{P})]$ \\
\hline & $2.3 \times 10^{8}$ & $1.73 \times 10^{6} \mathrm{~Pa} \cdot \mathrm{s}\left(1.73 \times 10^{7} \mathrm{P}\right)$ \\
\hline $373(100)$ & $3.1 \times 10^{8}$ & $9.93 \times 10^{5} \mathrm{~Pa} \cdot \mathrm{s}\left(9.93 \times 10^{6} \mathrm{P}\right)$ \\
\hline (200) & $3.8 \times 10^{8}$ & $6.98 \times 10^{5} \mathrm{~Pa} \cdot \mathrm{s}\left(6.98 \times 10^{6} \mathrm{P}\right)$ \\
\hline $573(300)$ & $2.7 \times 10^{8}$ & $5.79 \times 10^{5} \mathrm{~Pa} \cdot \mathrm{s}\left(5.79 \times 10^{6} \mathrm{P}\right)$ \\
\hline
\end{tabular}

Table IV. Parameters of Function $\sigma_{w}=\sigma^{\prime}+\eta \cdot \dot{\varepsilon}$, for Aluminum Subjected to Extrusion by the КОBO Method
The values of relaxation times determined for different temperatures and different relationships between stress and the rate of extrusion also allowed calculation of the parameters that identify the mechanism of the process in the scale of atoms. These parameters are activation energy, $E_{a}$, of elementary relaxation "act" (event) and activated volume, $V_{a}$, which is interpreted as the geometric measure of the area where thermal activation supports (with the probability according to Boltzmann energy distribution) the relaxation event.

Relaxation time, as the reciprocal value of the number of events subjected to Maxwell-Boltzmann statistics, is defined as

$$
\tau_{r}=\tau_{o} \exp \left(E_{a} / \mathrm{k} \cdot T\right)
$$

where $\tau_{o}$ is a characteristic time constant, $E_{a}$ is the activation energy, $\mathrm{k}$ is the Boltzmann constant, and $T$ is the temperature in absolute scale.

Experimental data presented in the form of a system in coordinates $\ln \left(\tau_{r}\right)-T^{-1}$ exhibit a linear relationship (Figure 30), while the interpolation function

$$
\ln \left(\tau_{r}\right)=-10.7322+0.0568 T^{-1}
$$

returns the values

$$
\tau_{o}=2.18 \cdot 10^{-5} \mathrm{~s}
$$

And

$$
E_{a}=9.0999 \cdot 10^{-21} \mathrm{~J}(0.0568 \mathrm{eV})
$$

On the other hand, as a basis to determine the activated volume, a function describing the kinetics of

Table V. Dependence of Relaxation Time $\tau_{r}$ on the Temperature $T$

\begin{tabular}{lc}
\hline Temperature $T\left[\mathrm{~K}\left({ }^{\circ} \mathrm{C}\right)\right]$ & Relaxation Time $\tau_{r} s$ \\
\hline $293(20)$ & $2.14 \times 10^{-4}$ \\
$373(100)$ & $1.23 \times 10^{-4}$ \\
$473(200)$ & $8.61 \times 10^{-5}$ \\
$573(300)$ & $7.16 \times 10^{-5}$ \\
\hline
\end{tabular}

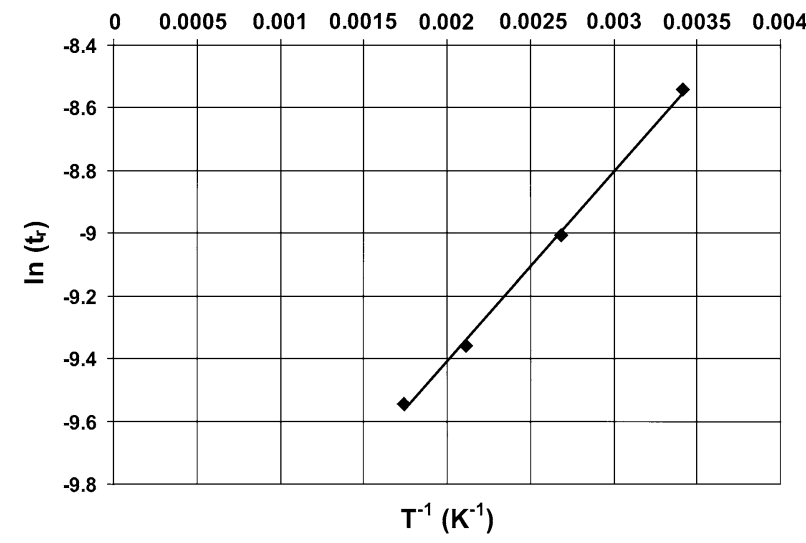

Fig. 30-Dependence of relaxation time $\ln \left(t_{r}\right)$ on the inverse of temperature in absolute scale $\left(T^{-1}\right)$. 
Table VI. Activated Volume of KOBO Extrusion with KOBO Process $(\alpha= \pm 8 \mathrm{Deg}, f=5 \mathrm{~Hz})$ of Aluminum at Extrusion Ratio $\lambda=100$, Depending on the Temperature

Process Temperature $\left[\mathrm{K}\left({ }^{\circ} \mathrm{C}\right)\right]$

Activated Volume $\left(\mathrm{m}^{3}\right)$

$293(20)$

$373(100)$

$473(200)$

$573(300)$

$4.40 \times 10^{-29}$

$4.65 \times 10^{-29}$

$4.28 \times 10^{-29}$

$5.20 \times 10^{-29}$

thermally activated processes can be used, which, in the case of plastic deformation, becomes

$$
\stackrel{\prime}{\varepsilon}=\stackrel{\prime}{\varepsilon_{o}} \cdot \exp \left[-\left(E_{a}-\sigma_{e f} \cdot V_{a}\right) / \mathrm{k} \cdot T\right]
$$

where $\hat{\varepsilon}_{o}$ is a frequency parameter of the process, $E_{a}$ is the activation energy, $\sigma_{e f}$ is the effective stress acting within the activated area, $V_{a}$ is the activated volume, $\mathrm{k}$ is the Boltzmann constant, and $T$ the temperature in absolute scale.

Thus, the activated volume equals

$$
V_{a}=\mathrm{k} \cdot T \cdot d \ln \frac{\prime}{\varepsilon} / d \sigma
$$

and its averaged values are presented in Table VI.

The determined size of the activated volume is roughly twice the atomic volume of aluminum, which is calculated on the basis of the lattice parameter and equals $2.33 \times 10^{-29} \mathrm{~m}^{3}$.

In light of the structural interpretation, the result obtained confirms an earlier articulated suggestion that the point defects decide on the plastic resistance (viscosity) of metal in conditions of the process being analyzed. This conclusion lends more detail to the calculation of the activation energy value, which, at the level of $9.6 \cdot 10^{-21} \mathrm{~J}(0.06 \mathrm{eV})$, corresponds to the migration energy of interstitial atoms (Frenkel defects) defined in previous works. ${ }^{[5-57]}$

Conducted structural analysis and studies of kinetics, therefore, cast a new light on the process of plastic flow mechanism during large deformations running in the conditions of "cyclic changes of deformation path," revealing the characteristics of viscous fluid flow. On the other hand, assuming that the viscous character of plastic flow decides the diffusion of point defects (Frenkel defects) generated in the KOBO process in excess in relation to the state of equilibrium, the factor controlling the process is their mobility understood as the frequency of defect (atom) displacement, of which the measurement is the inverse of relaxation time $\left(\tau^{-1}\right)$. Function $^{[2]}$ shows that the time constant $\tau_{o}$ is the relaxation time when the energy of atom's jump $\left(E_{a}\right)$ equals zero. When the frequency of atoms' vibrations in the lattice (Debye frequency) is at the level of $v=10^{13} \mathrm{~s}^{-1}$, the volume $\tau_{o}$ of the order of $10^{5}$ per second means that only $10^{8}$ to $10^{13}$ vibrations per second will be effective vibrations (causing the displacement of the atom). The quotient value of $\tau_{o}$ by Debye frequency $v$ is thus identified, with point defect concentration responsible for the relaxing process:

$$
c_{a t}=\tau_{o} / v
$$

The value of $c_{a t}$ of the order $10^{-8}$ is evaluated on the assumption of homogenous distribution of defects in the metal volume and, in light of the flow line distributions (Figure 23), is highly underestimated. Nevertheless, the considerations carried out show that, in conditions in which point defects (Frenkel defects) are generated with an average concentration at the level of $10^{-8}$, it is possible to decrease the viscosity coefficient $\eta$ of metals by 10 to 20 orders of magnitude, what causes that under the influence of forces similar to the behavior of viscous liquid. Hence, the generation of point defects due to intersecting dislocations creates an opportunity to obtain the desired concentration of defects, and the factors controlling it are the density of dislocations intersecting each other and the frequency of intersections in the unit time.

\section{SUMMARY}

Based on the research and analysis presented in this work, a picture of metal plastic deformation was revealed as the viscous fluid flow process. In light of the knowledge about the mechanisms of low-temperature plastic deformation, such a picture forces verification of the views on the metal nature. In particular, the question arises about the actual role of point defects in the process of deformation. At low temperatures (homologous temperature $T / T_{\text {melt }}$ within the range of 0 to 0.4 ), this role is, in fact, ignored or point defects are treated as a component of the mechanism of dynamic recovery (unrated quantitatively). The second extreme approach, now having more historical value, is the assignment of the generated vacancies, the role of cause factor for nonhomogeneous deformation of PortevinLeChatelier type, interpreted as the result of diffusioncontrolled dynamic aging.

In the context of well-known literature data and the results obtained in this work, one can distinguish two different reactions of materials subjected to SPD processing, although both lead to a strong structural fragmentation of products (nanostructure). The first, occurring during the extrusion with the KOBO method, appears regardless of the temperature but requires specific conditions for the process defined with adequate kinetics guaranteed by a high frequency of changes in deformation path (cyclic torsion of metal), very high deformation rate, and high extrusion ratio. It is related to a strong activation of low energetic deformation mechanism based on visco-plastic flow conditioned on very intensive generation and migration of interstitial atoms. In particular, the cyclic torsion results in simultaneous intersections of dislocations in extruded material and creation of jogs, which "hauling" leads to intense generation of point defects, the permanent destabilization of the structure, and localized plastic flow in shear bands. The similar effect may be caused due to formation dipoles by dislocations gliding in opposite directions. Despite the short "life" time of a single defect, a very high concentration of interstitial atoms is maintained in the material of extremely low 
energy of migration, focused especially in privileged areas of shear bands. Hence, visco-plastic flow of material takes place under the influence of a much lower total deformation work, compared to the processes characterized by the presence of equilibrium and homogeneously distributed concentration of point defects. In appropriately selected conditions of extrusion with the KOBO method, Frenkel defects can achieve a very high concentration, although far insufficient to ensure the realization of the process with high extrusion ratio by diffusive mass transport (true strain). Therefore, the role of interstitial atoms should be ascribed to the weakening of the crystal lattice bonds of material, particularly in the areas between the "blocks" of material cut by the shear bands, and thereby facilitate their mutual movement under the influence of low flow stress. Moreover, an extremely important effect of the presence of a large number of interstitial atoms capable of migration is their participation in intense arranging of the structure of the product; in particular, the dislocation climbing and creating recovered (quasi-recrystallized) very fine grains/subgrains even without thermal support (heating the material).

Other behavior concerns the materials not subjected to deformation in conditions of cyclic changes of deformation path or too low frequency of these changes. With natural tendency of material to achieve equilibrium concentration of point defects, low frequency of changes in deformation path, as well as unloading the material before such a change (changes), would not provide continuous maintenance of high concentration of interstitial atoms in the material. Hence, the plastic deformation of materials, despite the dominance of a mechanism of localized flow in shear bands, requires the involvement of large deformation work. Moreover, in accordance with relatively low concentration of interstitial atoms, substantial structural reconstruction, reflected in the "cleansing" of grains' interior (subgrains) and forming of their boundaries, does not take place in the product. Of course, running the process at a higher temperature would activate the recovery or recrystallization phenomena, and could foster a dynamic and, hence, hardly controlled grain coarsening.

\section{ACKNOWLEDGMENTS}

This work received financial support from the Ministry of Science and Higher Education of Poland under Research Project Nos. PBZ-KBN-102/T08/2003 and 11.11.180.448.

\section{OPEN ACCESS}

This article is distributed under the terms of the Creative Commons Attribution Noncommercial License which permits any noncommercial use, distribution, and reproduction in any medium, provided the original author(s) and source are credited.

\section{REFERENCES}

1. A.H. Cottrell and R.J. Stokes: Proc. R. Soc., 1955, vol. A233, pp. 17-34.

2. Z.S. Basinski and P.J. Jackson: Phys. Status Solidi, 1965, vol. 10, pp. $45-56$.

3. Z.S. Basinski and P.J. Jackson: Phys. Status Solidi, 1967, vol. 9, pp. 805-23.

4. A. Korbel and M. Szczerba: Acta Metall., 1982, vol. 30, pp. 1961-68.

5. W. Bochniak: Mater. Sci. Eng., 1995, vol. A190, pp. 81-86.

6. W. Bochniak: Z. Metallkd., 1999, vol. 90, pp. 153-58.

7. A. Azushima and K. Aoki: Mater. Sci. Eng., 2002, vol. A337, pp. 45-49.

8. R. Song, D. Ponge, D. Raabe, J.G. Speer, and D.K. Matlock: Mater. Sci. Eng., 2006, vol. A441, pp. 1-17.

9. Q. Wei, S. Cheng, K.T. Ramesh, and E. Ma: Mater. Sci. Eng., 2004, vol. A381, pp. 71-79.

10. K.S. Kumar, H. Van Swygenhoren, and S. Suresh: Acta Mater., 2003, vol. 51, pp. 5743-74.

11. M.A. Meyers, A. Mishra, and D.J. Benson: Prog. Mater. Sci., 2006, vol. 51, pp. 427-556.

12. Q. Wei, L. Kecskes, T. Jiao, K.T. Hartwig, K.T. Ramesh, and E. Ma: Acta Mater., 2004, vol. 52, pp. 1859-69.

13. K.S. Kumar, S. Suresh, M.F. Chisholm, J.A. Horton, and P. Wang: Acta Mater., 2003, vol. 51, pp. 387-405.

14. M. Legros, B.R. Elliott, M.N. Rittner, J.R. Weertman, and K.J. Hemkar: Philos. Mag., 2000, vol. A89, pp. 1017-26.

15. H. Van Swygenhoven, M. Spaczer, A. Caro, and D. Farkas: Phys. Rev., 1999, vol. B60, pp. 22-25.

16. Y. Yamakov, D. Wolf, S.R. Phillpot, A.K. Mukherjee, and H. Gleiter: Nat. Mater., 2002, vol. 1, pp. 45-49.

17. Y. Wang, M. Chen, F. Zhou, and E. Ma: Nature, 2002, vol. 419, pp. $912-14$

18. X.Z. Liao, F. Zhou, E.J. Lavernia, S.G. Srinivasan, M.I. Baskes, D.W. He, and Y.T. Zhu: Appl. Phys. Lett., 2003, vol. 83, pp. 63234.

19. L. del Bianco, A. Hernando, E. Bonetti, and E. Nanarro: Phys. Rev., 1997, vol. B56, pp. 8894-8901.

20. S.A. Shei and T.G. Langdon: Acta Metall., 1978, vol. 26, pp. 638-46.

21. D.J. Dingley: Proceedings III Annual Scanning Electron Microscope Symposium, Research Institute, Chicago, IL, 1970.

22. D. Jia, Y.M. Wang, K.T. Ramesh, E. Ma, Y.T. Zhu, and R.Z. Valiev: Appl. Phys. Lett., 2001, vol. 79, pp. 611-13.

23. Y.M. Wang, E. Ma, and M.W. Chen: Appl. Phys. Lett., 2002, vol. 80, pp. 2395-97.

24. X. Jiang and C.L. Jia: Appl. Phys. Lett., 1996, vol. 69, pp. 3902-04.

25. A.H. Chokshi, A. Rosen, J. Karch, and H. Gleiter: Scripta Metall., 1989, vol. 23, pp. 1679-86.

26. H. Van Swygenhoven and P.M. Derlet: Phys. Rev., 2001, vol. B64, 224105 , pp. $1-8$.

27. M. Murayama, J.M. Howe, H. Hidaka, and S. Takaki: Science, 2002, vol. 295, pp. 2433-35.

28. I.A. Ovid'ko: Science, 2002, vol. 295, p. 2386.

29. T. Meyer and H. von Känel: Phys. Rev. Lett., 1997, vol. 78, pp. 3133-36.

30. A. Ball and M.M. Hutchinson: J. Mater. Sci., 1969, vol. 3, pp. 1-7.

31. A. Hasnaoui, H. van Swygenhoven, and P.M. Derlet: Phys. Rev., 2002, vol. B66, 184112, pp. 1-9.

32. M. Lagos: Phys. Rev. Lett., 2000, vol. 85, pp. 2332-35.

33. V.M. Segal: Mater. Sci. Eng., 1995, vol. A197, pp. 157-64.

34. Y. Iwahashi, J.T. Wang, Z. Horita, M. Nemoto, and T.G. Langdon: Scripta Mater., 1996, vol. 35, pp. 143-46.

35. Y. Iwahashi, Z. Horita, M. Nemoto, and T.G. Langdon: Acta Mater., 1998, vol. 46, pp. 3317-31.

36. M. Furukawa, Z. Horita, M. Nemoto, and T.G. Langdon: J. Mater. Sci., 2001, vol. 36, pp. 2835-43.

37. V.M. Segal: Mater. Sci. Eng., 2002, vol. A338, pp. 331-44.

38. M.V. Markushev, C.C. Bampton, M.Y. Murashkin, and D.A. Hardwick: Mater. Sci. Eng., 1997, vols. A234-236, pp. 927-31.

39. P.W. Bridgeman: Studies in Large Plastic Flow and Fracture, McGraw Hill, New York, NY, 1952.

40. A.P. Zhilyaev, S. Lee, G.V. Nurislamova, R.Z. Valiev, and T.G. Langdon: Scripta Mater., 2001, vol. 44, pp. 2753-58. 
41. A.P. Zhilyaev, G.V. Nurislamova, B.K. Kim, M.D. Baro, J.A. Szpunar, and T.G. Langdon: Acta Mater., 2003, vol. 51, pp. 753-65.

42. Z. Lee, F. Zhou, R.Z. Valiev, E.J. Lavernia, and S.R. Nutt: Scripta Mater., 2004, vol. 51, pp. 209-14.

43. Y. Saito, H. Utsunomuja, N. Tsuji, and T. Sakai: Acta Mater., 1999, vol. 47, pp. 579-83.

44. N. Tsuji, R. Reji, Y. Minamino, and Y. Saito: Scripta Mater., 2002, vol. 46, pp. 305-10.

45. N. Tsuji, Y. Saito, H. Utsunomiya, and S. Tanigawa: Scripta Mater., 1999, vol. 40, pp. 795-800.

46. N. Tsuji, T. Iwata, M. Sato, S. Fujimoto, and Y. Minamino: Sci. Technol. Adv. Mater., 2004, vol. 5, pp. 173-80.

47. H.S. Kim: Mater. Sci. Eng., 2002, vol. A328, pp. 317-23.

48. J.T. Wang, Z.Z. Du, F. Kang, and G. Chen: Mater. Sci. Forum, 2006, vols. 503-504, pp. 663-68.

49. T.C. Lowe: Mater. Sci. Forum, 2006, vols. 503-504, pp. 355-62.
50. A. Korbel and W. Bochniak: Method of Plastic Forming of Materials, U.S. Patent 5,737,959 (1998), European Patent $0,711,210$ (2000).

51. W. Bochniak, K. Marszowski, and A. Korbel: J. Mater. Proc. Technol., 2005, vol. 169, pp. 44-53.

52. A. Korbel and W. Bochniak: Scripta Mater., 2004, vol. 51, pp. 755-59.

53. W. Bochniak and A. Korbel: Mater. Sci. Technol., 2000, vol. 16, pp. 664-74.

54. L. Madej, P.D. Hodgson, and M. Pietrzyk: Comput. Mater. Sci., 2007, vol. 38, pp. 685-91.

55. A.C. Damsk and G.J. Dienes: Point Defects in Metals, Gordon and Breach Science Publishers, New York, NY, 1963.

56. D. Terentyev and L. Malerba: J. Nucl. Mater., 2004, vols. 329333, pp. 1161-65.

57. K. Sato, T. Yoshiie, and Q. Xu: J. Nucl. Mater., 2007, vols. 367370 , pp. $382-85$. 